\section{A) Check for updates}

Cite this: Polym. Chem., 2018, 9, 4218

\title{
Amphiphilic polypyrrole-poly(Schiff base) copolymers with poly(ethylene glycol) side chains: synthesis, properties and applications $\uparrow$
}

\author{
Brenda G. Molina, (DD a,b Luminita Cianga, ${ }^{c}$ Anca-Dana Bendrea, ${ }^{c}$ Ioan Cianga, ${ }^{* c}$ \\ Luis J. del Valle, (D) ${ }^{a, b}$ Francesc Estrany, (D) ${ }^{a, b}$ Carlos Alemán (D) ${ }^{* a, b}$ and \\ Elaine Armelin (D)*a,b
}

\begin{abstract}
New amphiphilic poly(ethylene glycol) (PEG)-grafted random intrinsically conducting copolymers which combine three different functionalities have been engineered, prepared and characterized. Specifically, these "rod-coil" type copolymers bear conducting polypyrrole (PPy) and poly(Schiff base) (PSB) sequences randomly distributed in their backbones; hydrophilic grafted side chains consisting of well-defined PEG chains are attached to the PSB units. Basically, the synthesis of the copolymers is conducted sequentially by employing the "macromonomer" technique via electrochemical co-polymerization of a bis (pyrrole) benzoic Schiff base-containing PEG macromonomer with pyrrole monomers. After investigation of the chemical and electrochemical properties of the synthesized copolymers, their advantages of multi-functionality in terms of biomedical applications have been demonstrated. More specifically, the conjugated PPy and PSB sequences enabled the grafted copolymers to exhibit great ability to catalyse the oxidation of serotonin, an important neurotransmitter found in blood platelets and in the central nervous systems of animals and humans. On the other hand, the enhanced biocompatibility in comparison with bare PPy is due to the presence of PEG side chains, while bacteriostatic activity against both Gram-negative and Gram-positive bacteria is imparted by the synergistic combination of the polycationic character of the PPy main chain with the benzoic Schiff base functional groups and with the bent-shaped architecture of the facially amphiphilic PSB sequences, respectively. Accordingly, these grafted copolymers are promising materials for developing implantable electrodes for serotonin detection which present the abovemen-

tioned characteristics.
\end{abstract}

Received 21st May 2018, Accepted 11th July 2018 DOI: $10.1039 /$ c8py00762d rsc.li/polymers

\section{Introduction}

Since their discovery, electroactive conjugated polymers, also known as intrinsically conducting polymers (ICPs), have been foreseen to be prospective materials with applications in many fields despite several obvious drawbacks related to their processing (innate rigidity, insolubility, and infusibility). Therefore, the discovery in the late $1980 \mathrm{~s}^{1}$ of the concept of flexible side chains as a "chemically bound solvent" for solu-

\footnotetext{
${ }^{a}$ Departament d'Enginyeria Química, EEBE, Universitat Politècnica de Catalunya, C/ Eduard Maristany, 10-14, Ed. I.2, 08019 Barcelona, Spain

${ }^{b}$ Barcelona Research Center for Multiscale Science and Engineering, Universitat Politècnica de Catalunya, C/ Eduard Maristany, 10-14, Ed. I.S, 08019 Barcelona, Spain.E-mail: carlos.aleman@upc.edu,elaine.armelin@upc.edu

"Petru Poni" Institute of Macromolecular Chemistry, 41A, Grigore-Ghica Voda Alley, 700487 Iasi, Romania.E-mail: ioanc@icmpp.ro

$\dagger$ Electronic supplementary information (ESI) available. See DOI: 10.1039/ c8py00762d
}

bilizing the rod-like ICPs was welcome; this discovery enabled the development of currently well-known solution processing technologies, although it was demonstrated that the introduction of alkyl or alkoxy side chains alters the planarity of the conjugated backbone by their steric interaction, thus negatively affecting the electrical conductivity and decisively influencing the spectral features and specific phase behaviour. ${ }^{2}$

However, in recent years, ICPs-based graft copolymers with linear biocompatible thermoplastics as side chains have emerged as a new class of useful hybrid materials. The advantage of the synergistic combination of very different characteristics and properties is due to the presence of the semiconducting main chain and grafted segments in a single structure. $^{3}$ The high conductivity, good capacitive behavior and wide range of unique electromechanical and electrochromic characteristics ${ }^{4-8}$ of ICPs differentiate them from thermoplastics, thermosets and elastomers. Moreover, these properties can be reversibly tuned through electrochemical reactions; thus, this class of materials are ideal biomimetic 
candidates for the development of biosensing devices, ${ }^{9-13}$ bioactuators, ${ }^{14-16}$ regulated drug-delivery systems, ${ }^{17-21}$ and bioelectrodes, among other biomedical applications. ${ }^{22-26}$

The design of new biocompatible conducting polymers using biodegradable thermoplastics is an exciting area of research. Ma and co-workers recently reported a review ${ }^{27}$ compiling the main studies on bioactive scaffolds for tissue regeneration that employ electrically conducting polymers, such as polyaniline (PAni) and oligomers, polypyrrole (PPy) and polythiophene (PTh) combined with poly(ethylene glycol) (PEG), ${ }^{28,29}$ polylactide (PLA), ${ }^{30}$ and polycaprolactone (PCL). ${ }^{31}$ Although amphiphilic conducting polymers for biomedical functions have not been yet extensively addressed, systems derived from polypyrrole (PPy) and polythiophene (PTh) are among the most well studied. For example, $\mathrm{pH}$ responsive PTh- $g$-poly $(N, N$-dimethylaminoethylmethacrylate) (PTh- $g$ PDMA) was proposed as an aqueous sensor for biological applications, ${ }^{32}$ an amphiphilic copolymer consisting of a PTh backbone and sparsely attached oligo- $\varepsilon$-caprolactone side chains (PTh- $g$-PCL) was proven effective as a dopamine biosensor, ${ }^{33}$ and PPy-g-poly(styrenesulfonic acid) (PPy- $g$-PSSA) was used for the electrocatalytic biosensing of hypoxanthine. ${ }^{34}$ Also, functionalized PTh-graft copolymers have been designed to effectively induce specific adsorption of cells and proteins. ${ }^{35,36}$ In the last few years, most of our research interest in PTh-graft copolymers for biomedical applications has been focused on systems containing PEG side chains anchored to a PTh backbone (PTh- $g$-PEG). ${ }^{1,37-41}$ For example, we used pentathiophene-PEG macromonomers $\left(\mathrm{Th}_{5}-\mathrm{PEG}_{M}\right.$, where $M$ refers to the molecular weight of the PEG side chain, with $M_{\mathrm{n}}=$ 1000 or $2000 \mathrm{~g} \mathrm{~mol}^{-1}$ ) to produce graft copolymers, denoted as $\mathrm{PTh}_{5}-\mathrm{g}-\mathrm{PEG}_{M}$ (Scheme 1). ${ }^{1,38,40}$ These materials were successfully employed as active surfaces for the selective adsorption of proteins and as cellular matrices for tissue engineering.

More recently, we synthesized $\mathrm{PTh}_{3}-\mathrm{g}-\mathrm{PEG}_{2000}$ copolymers (Scheme 2) via a macromonomer approach using a terthiophene-PEG macromonomer $\left(\mathrm{Th}_{3}-\mathrm{PEG}_{2000}\right)$ copolymerized with terthiophene $\left(\mathrm{Th}_{3}\right)$ using different $\mathrm{Th}_{3}-\mathrm{PEG}_{2000}: \mathrm{Th}_{3}$ ratios. ${ }^{40}$ These materials showed excellent behavior as bioactive platforms; they were more biocompatible in terms of cellular adhesion and proliferation and more electroactive than $\mathrm{PTh}_{5}-\mathrm{g}-\mathrm{PEG}_{M}$ (Scheme 1).

On the other hand, PSB are recognized ICPs ${ }^{42,43}$ with potential application areas ranging from LED devices, ${ }^{44}$ organic photovoltaics (OPV), ${ }^{45}$ and electrochromic devices (ECD) ${ }^{46}$ to organic field effect transistors (OFET) ${ }^{47}$ and chemosensors. ${ }^{48}$

In a series of reported studies on chemical and electrochemical syntheses of several bis(pyrrole) Schiff bases, ${ }^{49,50}$ investigations of their properties revealed that their electrical conductivities, ${ }^{49}$ redox properties ${ }^{51}$ and behaviour in electrochemical polymerization $^{52}$ are similar to those of polypyrrole. In another approach, a polystyrene-containing bis(pyrrole) Schiff base macromonomer was prepared, ${ }^{53}$ and its copolymer with pyrrole showed interesting electrochromic properties. ${ }^{46}$

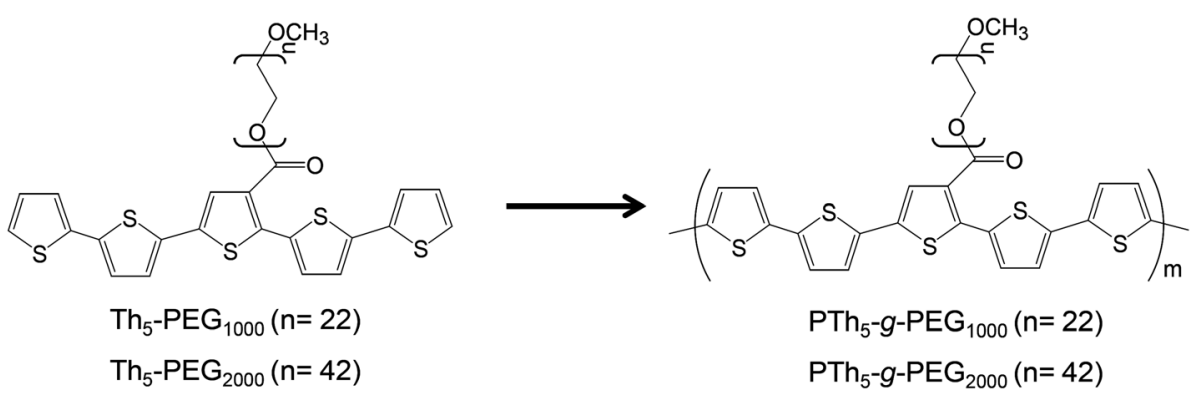

Scheme 1 Synthesis of $\mathrm{PTh}_{5}-g-\mathrm{PEG}_{M}{ }^{38}$

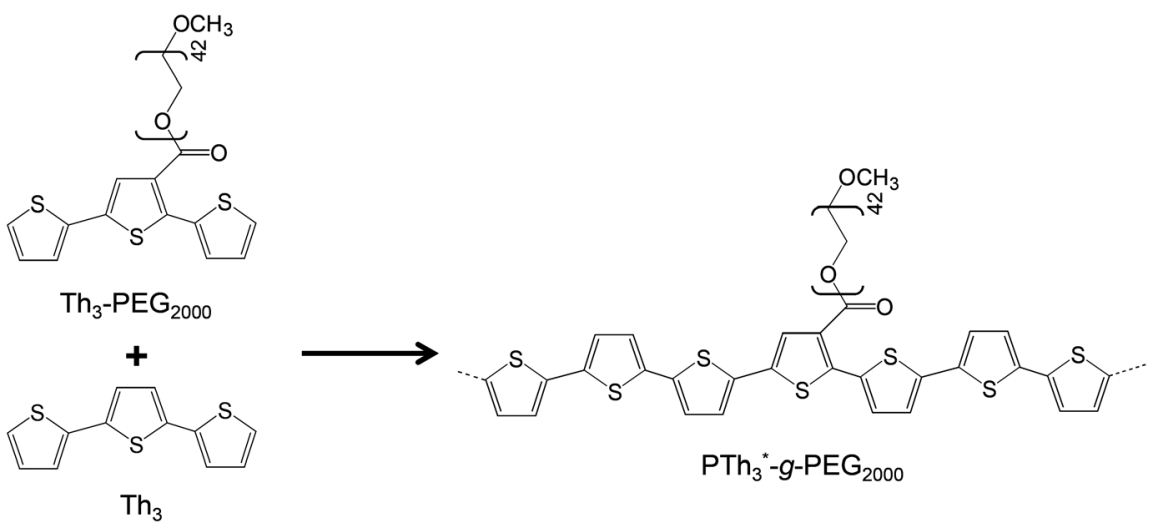

Scheme 2 Synthesis of $\mathrm{PTh}_{3}-g-\mathrm{PEG}_{2000}$ copolymers. ${ }^{40}$ 
When biomedical applications are considered, even if PSB are well-recognized pharmacophores, their application as excellent plasmid DNA damage protecting agents ${ }^{54}$ or as wellperforming nonviral vectors for efficient cellular DNA transfection has also been reported. ${ }^{55}$ Also, in a recent study, we prepared new functional synthetic biomaterials with similar optical properties to those displayed by PTh by combining Schiff base functions with Th units in the polymeric main chain. ${ }^{56}$ More specifically, a Schiff base-containing bis-thienyl monomer, (AzbT), was synthesized and electrochemically copolymerized with $\mathrm{Th}_{3}$ using different AzbT: $\mathrm{Th}_{3}$ ratios (Scheme 3). The resulting $\mathrm{P}\left(\mathrm{AzbT}-\mathrm{co}-\mathrm{Th}_{3}\right)$ copolymers behaved as bioactive substrates that promoted cellular viability; this was attributed to the presence of hydrophilic pendant carboxyl groups. Moreover, the antibacterial activity, usually associated with the presence of the Schiff base functionality, suggested that the $\mathrm{P}\left(\mathrm{AzbT}-\mathrm{co}-\mathrm{Th}_{3}\right)$ construction can be considered as a dual-functionalized platform for advanced biomedical applications. The introduction of inherent antibacterial ability into materials for tissue engineering scaffolds, cell therapy or other bio-applications brings benefits, such as decreased infection risk.

In the present work, new amphiphilic random copolymers are reported that combine the benefits associated with both the graft PEG chains and the presence of a benzoic Schiff base in a polyheterocyclic backbone. For this purpose, in analogy with AzbT reported in our previous study, ${ }^{56}$ a new macromonomer has been designed and subsequently synthesized in two reaction steps. More specifically, in this new compound, the end-thienyl moieties of AzbT have been replaced by pyrrole (Py) units, while the carboxyl moiety of the aromatic phenyl ring has been used to attach $\mathrm{PEG}_{2000}$ side chains. After synthesizing and characterizing the macromonomer, hereafter denoted AzbPy- $g$-PEG, it was electrochemically copolymerized with Py, and the chemical and physical properties of the resulting graft copolymers, $\mathrm{P}(\mathrm{Py}-\mathrm{co}-\mathrm{AzbPy}-\mathrm{g}$-PEG), were determined. Finally, the suitability of $\mathrm{P}(\mathrm{Py}-\mathrm{Co}-\mathrm{AzbPy}-\mathrm{g}$-PEG) in potential bioactive and biosensing platforms has been considered. Thus, studies on the protein adhesion, cellular proliferation, anti-
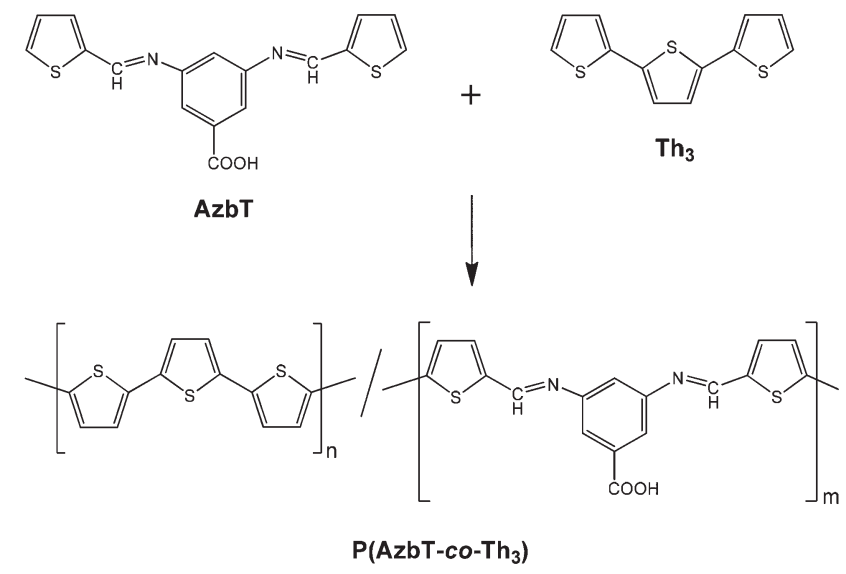

Scheme 3 Synthesis of $\mathrm{P}\left(\mathrm{AzbT}-\mathrm{co}-\mathrm{Th}_{3}\right)$ copolymers. ${ }^{56}$ microbial activity, and neurotransmitter detection biocapacities of P(Py-co-AzbPy-g-PEG) are also discussed.

\section{Experimental section}

\section{Materials}

Pyrrole (Py; from Aldrich, 98\%) was freshly distilled and 2-pyrrole-carboxaldehyde (from Fluka, 97\%) was recrystallized from petroleum ether before use. $p$-Toluenesulfonic acid (PTSA; from Aldrich, 99\%) and 3,5-diaminobenzoic acid (DABA; from Aldrich, 98\%), poly(ethylene glycol) methyl ether with $M_{\mathrm{n}}=2000 \mathrm{~g} \mathrm{~mol}^{-1}$ ( $\mathrm{PEG}_{2000}$; from Aldrich), $N, N^{\prime}$-dicyclohexylcarbodiimide (DCCI; from Merck), 4-dimethylamino pyridine (DMAP; from Aldrich) and acetonitrile (ACN; from Panreac S.A., PA) were used as received. Meanwhile, anhydrous lithium perchlorate (from Sigma-Aldrich, 95\%) was stored in an oven at $70^{\circ} \mathrm{C}$ before its use in the electrochemical trials.

Synthesis of the azomethine-containing bis-pyrrole monomer: 3,5-bis(((E)-(1H-pyrrol-2-yl)methylene)amino)benzoic acid (AzbPyBA)

A $250 \mathrm{~mL}$ three-neck round bottom flask equipped with a condenser, a Dean-Stark trap, a nitrogen inlet-outlet and a magnetic stirrer was charged with 2-pyrrole-carboxaldehyde (5.89 g; $0.062 \mathrm{~mol})$, DABA (4.56 g, $0.03 \mathrm{~mol})$, PTSA (0.015 g) and toluene $(150 \mathrm{~mL})$. Nitrogen was purged through the reaction mixture for 15 minutes (Scheme 4).

The mixture was heated to reflux with stirring for 20 hours while continuously removing the toluene-water azeotrope. After cooling the reaction mixture, the formed solid product was filtered and purified by column chromatography (aluminum oxide-Fluka Type 507c), first with dichloromethane as eluent and then with THF. The second fraction was concentrated by evaporation under reduced pressure, and the resulting dark-brown solid was dried. A dark-brownish solid was obtained. Yield: $62 \%$.

\section{Synthesis of pyrrole- $g$-polyethylene glycol macromonomer functionalized with azomethine-containing bis-pyrrole moieties (AzbPy-g-PEG)}

$2 \mathrm{~g}(0.001 \mathrm{~mol})$ of $\mathrm{PEG}_{2000}$ and $0.46 \mathrm{~g}(0.0015 \mathrm{~mol})$ of AzbPyBA were placed in a three-neck round-bottom flask equipped with a dropping funnel under nitrogen. $17 \mathrm{~mL}$ of $\mathrm{THF}$ and $0.01815 \mathrm{~g}(0.00015 \mathrm{~mol})$ of DMAP were added to the flask. $0.3078 \mathrm{~g}(0.0015 \mathrm{~mol})$ of DCCI in $1.5 \mathrm{~mL}$ THF were placed in the dropping funnel and added over about $15 \mathrm{~min}$. The mixture was stirred at room temperature for three days (Scheme 4). The resulting solution was filtered and precipitated in cold diethyl ether to remove the catalyst and the unreacted reagents. After filtration and drying, a white solid was obtained. The product was passed through a silica gelfilled column and re-precipitated in cold diethyl ether using $\mathrm{CH}_{2} \mathrm{Cl}_{2}$ as solvent. 
<smiles>Nc1cc(N)cc(C(=O)O)c1</smiles>

DABA<smiles>O=C(O)c1cc(/N=C/c2ccc[nH]2)cc(/N=C/c2ccc[nH]2)c1</smiles>

AzbPyBA

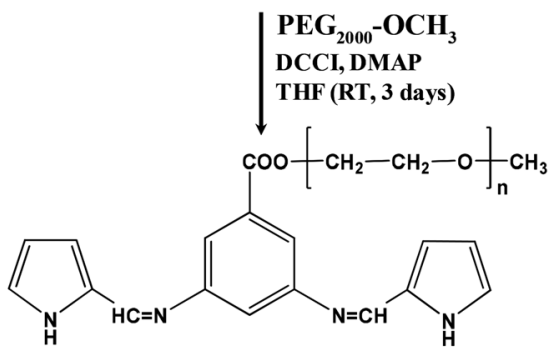

AzbPy-g-PEG

Copolymerization of pyrrole monomer and pyrrole- $g$-polyethylene glycol macromonomer to obtain P(Py-co-AzbPy- $g$-PEG)

All electrochemical assays, including anodic polymerizations, were carried out in a standard $50 \mathrm{~mL}$ three-electrode cell under nitrogen atmosphere (99.995\% purity) at room temperature. The anodic compartment was filled with $10 \mathrm{~mL}$ of a $1 \mathrm{mM} 1$ : 1 Py: AzbPy-g-PEG in ACN solution with $0.1 \mathrm{M} \mathrm{LiClO}_{4}$ as the supporting electrolyte; meanwhile, the cathodic compartment was filled with $10 \mathrm{~mL}$ of the same electrolyte solution. Stainless steel (SS) AISI 316 sheets with areas of $0.5 \mathrm{~cm}^{2}$ (surface roughness determined by $\mathrm{AFM}, R_{\mathrm{q}}=11.4 \AA$ ) were employed as working electrodes (WE) and counter electrodes
(CE), respectively. The reference electrode (RE) was an $\mathrm{Ag} \mid \mathrm{AgCl}$ electrode containing a saturated aqueous $\mathrm{KCl}$ solution $\left(E^{\circ}=\right.$ $0.222 \mathrm{~V}$ at $25^{\circ} \mathrm{C}$ ) which was connected to the working compartment through a salt bridge containing the electrolyte solution. $\mathrm{P}(\mathrm{Py}-\mathrm{co}$-AzbPy- $g$-PEG) polymeric films were prepared by chronoamperometry (CA) using a constant potential of $+1.60 \mathrm{~V}$ and considering three different polymerization times $(\theta=300$, 500 and 1000 s) (Fig. 1). The stainless steel WE surfaces were covered by the polymers after the current pass and polymerization times were established. The final compositions of the monomer units in the copolymer films were determined by determining the ratios of the FTIR absorption bands for the $\mathrm{N}-\mathrm{H}$ stretching in the Py units (at $3430 \mathrm{~cm}^{-1}$ ) and the

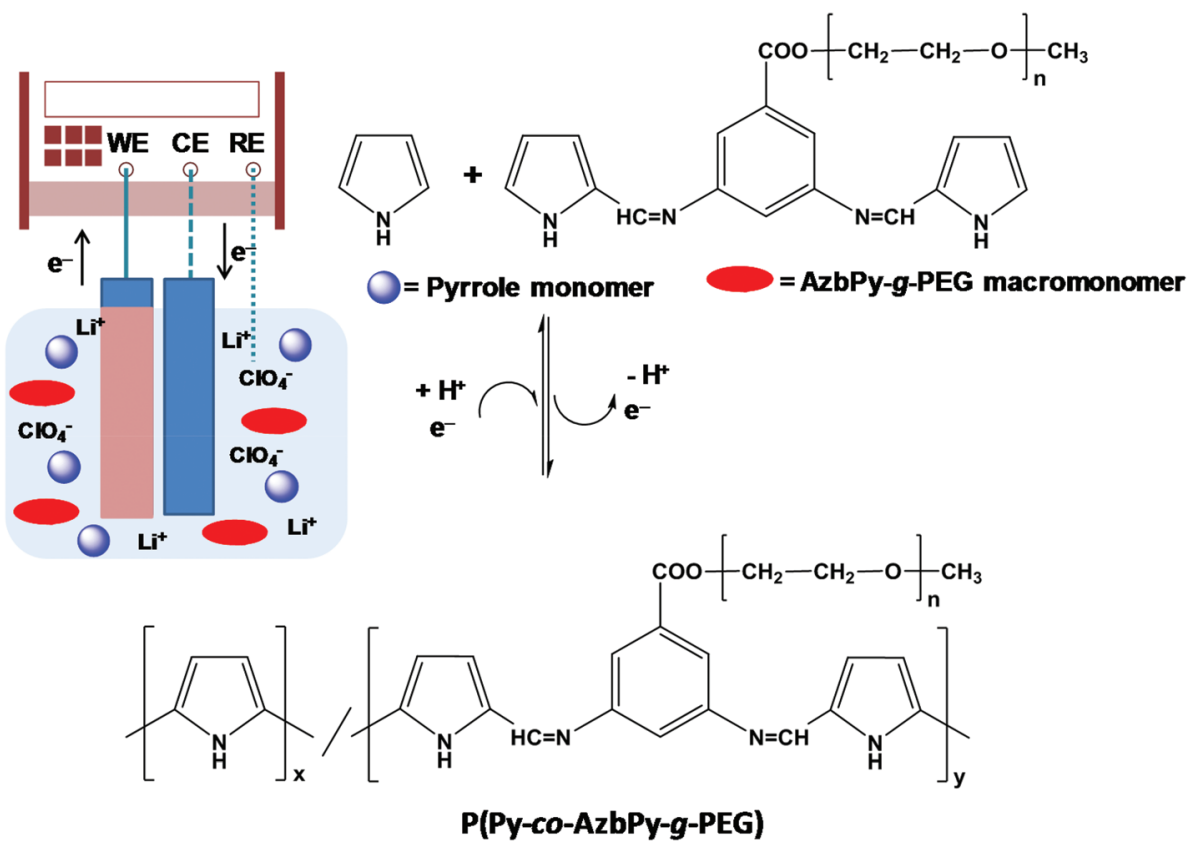

Fig. 1 Scheme illustrating the anodic polymerization of P(Py-co-AzbPy-g-PEG). The experimental conditions are described in the Methods section. 
ether deformation (at $1108 \mathrm{~cm}^{-1}$ ) in the PEG units. For calculations, the Py: PEG molar ratio (2:1) and the molecular weight of the macromonomer $\left(2313.4 \mathrm{~g} \mathrm{~mol}^{-1}\right)$ were taken into account.

PPy homopolymer (PPy) was also prepared and characterized as a standard for comparison of the properties of the copolymers. The generation medium was $1 \mathrm{mM}$ of Py in acetonitrile solvent, with $0.1 \mathrm{M} \mathrm{\textrm {LiClO } _ { 4 }}$ solution as the supporting electrolyte, and the anodic polymerization was performed using a constant potential of $+1.70 \mathrm{~V}$ for $\theta=300 \mathrm{~s}$.

\section{Characterization of the macromonomer and copolymers}

The AzbPy- $g$-PEG macromonomer was characterized by ${ }^{1} \mathrm{H}$ - and ${ }^{13} \mathrm{C}-\mathrm{NMR}$ spectroscopy, FTIR, UV-vis and fluorescence spectroscopies and thermal analyses. The experimental methods of all the characterization techniques for all the monomers and graft copolymers are detailed in the ESI. $\dagger$

\section{Biological studies}

In order to evaluate the ability of P(Py-co-AzbPy- $g$-PEG) to interact with different proteins, adsorption assays were conducted out using albumin (BSA) and lysozyme (Lyz) proteins. The cytotoxicity was evaluated using the COS-1 and Vero cell lines. Finally, the antimicrobial properties of AzbPy-g-PEG macromonomer, PPy and $\mathrm{P}(\mathrm{Py}-\mathrm{Co}-\mathrm{AzbPy}-\mathrm{g}$-PEG) were investigated using Escherichia coli (E. coli) and Staphylococcus aureus (S. aureus), which are Gram-negative and Gram-positive bacteria, respectively. The complete experimental procedures are described in the ESI. $\dagger$

\section{Electrochemical detection of serotonin neurotransmitter}

Differential pulse voltammetry (DPV) was applied for the electrochemical detection of serotonin. The assays were carried out in a tree electrode cell according to the procedure described in the ESI. $\dagger$

\section{Results and discussion}

\section{Design, synthesis and characterization of AzbPy-g-PEG macromonomer}

In a previous study, an electrochemically active bis-thienylcontaining monomer, AzbT, with preformed Schiff base linkages was synthesized starting from 2-thiophene carboxaldehyde and the versatile bis-aminoacid DABA, the presence of which enabled the preparation of $\mathrm{P}\left(\mathrm{AzbT}-\mathrm{co}-\mathrm{Th}_{3}\right)$ copolymers with free carboxyl functionality. ${ }^{56}$

In the present work, a similar approach was used; however, with the aim of encoding multifunctionality by design, several essential modifications were performed (Scheme 4). Firstly, the thienyl-end groups were replaced by pyrrole rings. As with thiophene, these moieties maintained their electrochemical activity; however, the obtained PPy, in its oxidized form, is a biocompatible polycation with recognized antibacterial activity in all its forms (powder, particles, nanotubes and thin film surfaces). ${ }^{57,58}$ The benzoic Schiff base bonds were retained for their potential antibacterial activity and also as desirable and easy-to-use functionalities for the construction of $\mathrm{pH}$-responsive systems. Benzoic Schiff bases are differentiated from other types of Schiff bases by their stability at normal physiological $\mathrm{pH}$ (7.4) and their ability to undergo hydrolysis under very mild acidic conditions ( $\mathrm{pH}$ 6.5-6.8). Due to this behavior, materials containing these functional bonds can find various practical applications, including transient scaffolds and transient bioelectronic devices. ${ }^{59}$ The presence of free carboxyl groups in AzbPyBA (Scheme 4) enabled the attachment of the non-ionic PEG by esterification in the second step of synthesis; thus, the structure of the new macromonomer AzbPy- $g$-PEG was amphiphilic, with high hydrophilicity, water dispersibility and the ability to complex with metal ions. ${ }^{60}$ Also, it is known that incorporation of hydrophilic moieties such as PEG can dramatically improve the biocompatibility of polycations without significant loss of antimicrobial activity. These modifications can be used to improve the selectivity of the antimicrobial agent towards bacteria over mammalian cells. ${ }^{61}$ Moreover, although they represent a nascent technique in the field, phase-separated amphiphilic copolymer coatings have significant potential to prevent bacterial infections on implanted medical devices. ${ }^{62}$ These coatings phase-separate on the length scale of biomacromolecules and disrupt their adhesion mechanisms. Last but not least in the importance order of the chemical-structural features of AzbPy- $g$-PEG is the bent-shaped geometry imposed by the 3,5-substituted phenyl ring from the DABA moiety, as well as the attachment of PEG side chains in the first position of this phenyl ring. Due to these structural peculiarities, the new macromonomer is a facially amphiphilic structure (FA). The importance of this aspect is related to the widespread FA in nature, from steroids to antimicrobial peptides, such as magainin, cecropin and defensins. For host defense peptides, it has been shown that this architecture is imperative for antibacterial activity and selectivity, rather than the precise chemical composition or amino acid sequence. ${ }^{63}$ Thus, synthetic polymers that mimic the essential physicochemical features of these specialized natural macromolecules can provide fast access to less expensive materials for medical coatings, antimicrobial tubing, and other applications. ${ }^{63}$

After the synthesis, the structures of the new compounds were unambiguously elucidated by combining FTIR, ${ }^{1} \mathrm{H}-\mathrm{NMR}$ and ${ }^{13} \mathrm{C}$-NMR spectroscopy.

Fig. 2 compares the FTIR spectra of DABA, AzbPyBA and AzbPy- $g$-PEG. The spectrum of DABA presents the characteristic absorption bands of the primary aromatic amine functionality at $3427 \mathrm{~cm}^{-1}\left(\nu_{\text {asim }} \mathrm{NH}_{2}\right), 3339 \mathrm{~cm}^{-1}\left(\nu_{\text {sim }} \mathrm{NH}_{2}\right)$, and $1289 \mathrm{~cm}^{-1}$ and $1267 \mathrm{~cm}^{-1}\left(\nu \mathrm{C}-\mathrm{N}\right.$ of $\left.\mathrm{NH}_{2}\right)$; these are absent from the spectrum of AzbPyBA. The successful synthesis of the latter is corroborated by the new band at $1669 \mathrm{~cm}^{-1}(\nu \mathrm{C}=\mathrm{N})$, which is due to the formation of azomethine bonds, as well as by the appearance of bands typically associated with the Py ring. These are the broad band centered at $3344 \mathrm{~cm}^{-1}(\nu \mathrm{NH})$, the shoulder at $3124 \mathrm{~cm}^{-1}(\nu=\mathrm{C}-\mathrm{H})$, and other bands at $1089 \mathrm{~cm}^{-1}(\beta \mathrm{NH}), 1042 \mathrm{~cm}^{-1}$, and $960 \mathrm{~cm}^{-1}(\beta \mathrm{C}-\mathrm{H})$. 


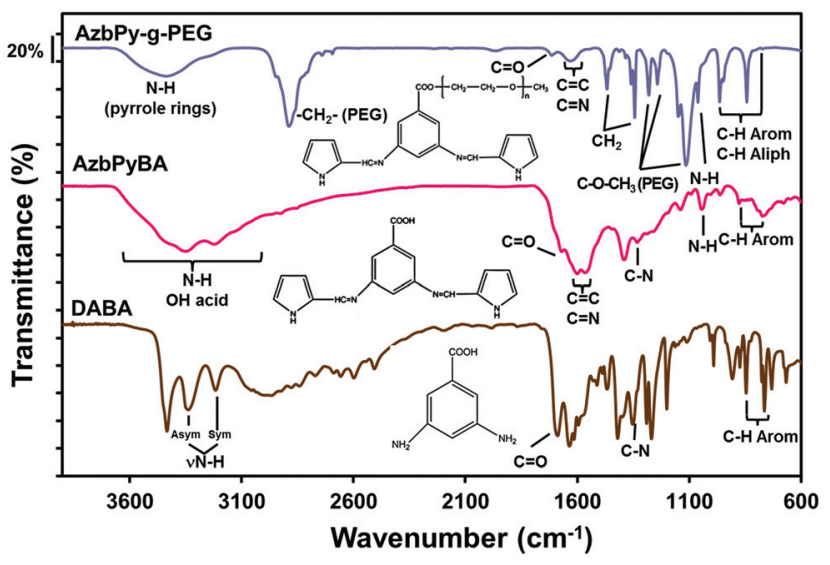

Fig. 2 FTIR spectra of AzbPy-g-PEG, AzbPyBA and DABA. The latter two compounds are the precursors used for the synthesis of the AzbPy$g$-PEG macromonomer.

On the other hand, the FTIR spectra of DABA and AzbPyBA reveal that both aromatic acids are in a dimerized form. Thus, the absorption bands due to the carbonyls of the carboxylic functionalities are centered at values $\left(1686 \mathrm{~cm}^{-1}\right.$ and $1701 \mathrm{~cm}^{-1}$ for DABA and AzbPyBA, respectively) lower than that typically found for the monomeric form $\left(\sim 1760 \mathrm{~cm}^{-1}\right)$. These bands are accompanied by other bands at $3212 \mathrm{~cm}^{-1}$ (DABA) and $3221 \mathrm{~cm}^{-1}$ (AzbPyBA), which are also specific for dimeric forms of aromatic acids. On further analysis, it can be observed that in the FTIR spectrum of AzbPy- $g$-PEG, the absorption band at $3221 \mathrm{~cm}^{-1}$ disappeared concomitantly with the appearance of a broad band centered at approximately $1715 \mathrm{~cm}^{-1}$ due to the formation of the ester group. The band at $1632 \mathrm{~cm}^{-1}$ in this spectrum was attributed to the azomethine bond. The presence of the PEG in the structure of AzbPy- $g$-PEG is confirmed by additional bands at 1360 , 1278 and $1059 \mathrm{~cm}^{-1}$ (common vibrations of crystallized PEG in a $7 / 2$ helical structure) in addition to those attributed to the trans zig-zag conformation at 1241 and $963 \mathrm{~cm}^{-1}$, supporting the assumption that PEG in AzbPy- $g$-PEG is in the crystallized form. ${ }^{64}$

The expected structures were also confirmed by NMR spectroscopy $\left({ }^{1} \mathrm{H}\right.$-NMR, $\left.{ }^{13} \mathrm{C}-\mathrm{NMR}\right)$. The solvents used to record the spectra were carefully chosen; on the one hand, both the structural peculiarities of the compounds and their possible particular interactions during the solution preparation and NMR recording were taken into account. On the other hand, care was taken to avoid eventual solvent interference with the signals of the investigated compounds. Thus, the spectrum of the precursor AzbPyBA, containing highly polar functional groups (carboxyl, imine, pyrrole ring), was recorded in polar DMSO- $\mathrm{d}_{6}$ for solubility reasons, despite the presence of an appreciable amount of water that can be associated with DMSO due to its hygroscopic nature. This remnant water can be detrimental to the Schiff base linkages, as previously described. ${ }^{56}$ In the case of the AzbPy- $g$-PEG macromonomer, a propensity for self-assembly (SA) in PEG-selective solvents such as DMSO ( $\left.\varepsilon=47, \delta_{\mathrm{t}}=26.7 \mathrm{MPa}^{1 / 2}\right)$ can be intuitively envisioned, driven by the synergetic combination of hydrophobic and $\pi-\pi$ stacking interactions. ${ }^{31}$ Thus, the less polar acetone- $\mathrm{d}_{6}$ $\left(\varepsilon=21, \delta_{\mathrm{t}}=19.9 \mathrm{MPa}^{1 / 2}\right)$ was employed for the NMR recording in order to decrease the solvent selectivity toward PEG $\left(\delta_{\mathrm{t}}=\right.$ $24 \mathrm{MPa}^{1 / 2}$ ) as much as possible and, thus, to avoid decreased intensity of the peaks for the hydrophobic and aromatic moieties in the spectrum due to SA. ${ }^{65}$ However, some water is present in acetone as well; consequently, the values of the integrals were weakly affected for both hydrophobic (slightly decreased) and hydrophilic moieties (slightly increased), as can be seen in the spectrum in Fig. 3a.

Fig. 3 also compares the ${ }^{1} \mathrm{H}$-NMR spectra of AzbPy- $g$-PEG and AzbPyBA. It is well known that polar solvents induce downfield shifting of signals. As the spectrum of the AzbPy- $g$ PEG macromonomer was recorded in acetone- $d_{6}$ (Fig. 3a), an upfield shifting for the peaks is expected in comparison with the spectrum of AzbPyBA, for which the more polar DMSO- $d_{6}$ solvent was used (Fig. 3b). In this case, this shifting was only appreciable for the $\mathrm{N}-\mathrm{H}$ proton of the Py ring (h type in the ${ }^{1} \mathrm{H}$-NMR spectrum in Fig. 3a). This phenomenon has been attributed to the higher sensitivity of the $\mathrm{N}-\mathrm{H}$ moiety towards solvent polarity in comparison with the other aromatic protons and to the enhanced electron density in the structure of AzbPy- $g$-PEG due to the presence of PEG. On the other hand, the ${ }^{1} \mathrm{H}$-NMR spectra displayed in Fig. 3 for the two compounds indicate that the azomethine functionality is stable in the registration conditions and that it is present in both the syn and anti-isomeric forms. ${ }^{56}$ The increased amount of syn-conformer in the case of AzbPy-g-PEG compared to the AzbPyBA organic molecule has been associated with the effect of the PEG chain grafted at the phenylene ring, which can modify its positions with respect to the azomethine linkage. ${ }^{66}$ Therefore, the presence of the hydrophilic PEG molecules increases the deviation from planarity about the azomethine bond due to steric interactions. ${ }^{67}$ The ${ }^{13} \mathrm{C}-\mathrm{NMR}$ spectra of AzbPyBA and AzbPy- $g$-PEG molecules are shown in Fig. S1. $\dagger$

The photochemical and thermal properties of the new macromonomer were also investigated and compared to those previously reported for the AzbT monomer (Scheme 3). ${ }^{56}$ Comparison of the UV-vis spectra indicates that the $\lambda_{\max }$ position does not vary when the thiophene rings in AzbT are replaced by Py rings in AzbPyBA. However, a notable shift was obtained when PEG was incorporated into the macromonomer (Fig. S2a $\dagger$ ); the band gap decreased by a factor of $20 \%$ with respect to the AzbPyBA precursor (Table 1). This behavior was attributed to the electron-donor character of the PEG graft chain. The optical band gap was estimated from the onset wavelength of optical absorption in DMSO solution $\left(E_{\mathrm{g}}=1240 /\right.$ $\left.\lambda_{\text {onset }}\right)$. The molar extinction coefficients $(\varepsilon)$ were calculated by applying the Lambert-Beer law at the values of $\lambda_{\max }$ in the 340 to $347 \mathrm{~nm}$ range.

In the case of the fluorescence studies, both the shape and the $\lambda_{\text {max }}$ of AzbPy- $g$-PEG reflect changes with respect to AzbT. ${ }^{56}$ The fluorescence curve of AzbT was reported to be bimodal, whereas AzbPy-g-PEG shows a non-symmetric monomodal 


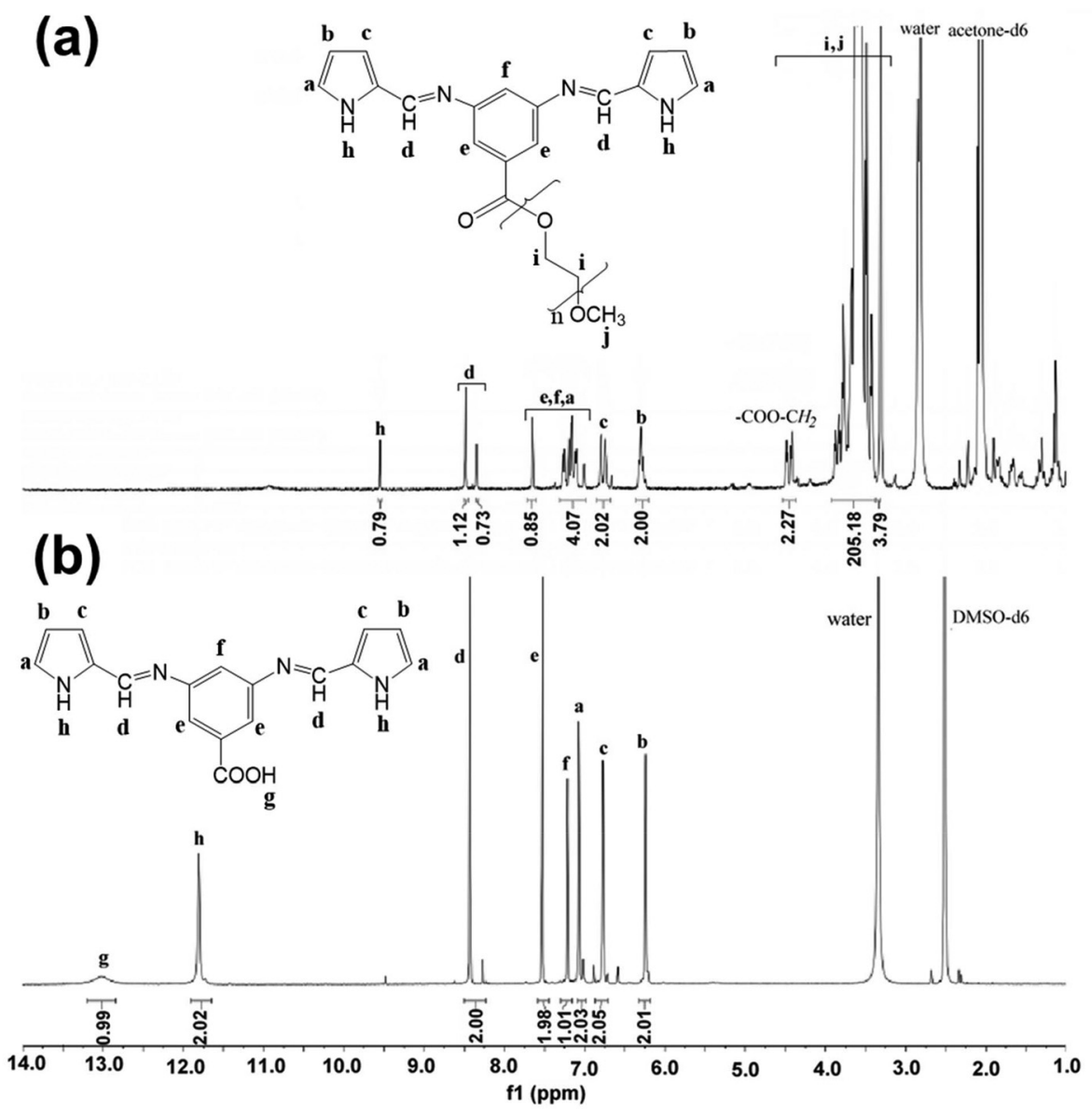

Fig. $3{ }^{1} \mathrm{H}-\mathrm{NMR}$ spectra of (a) AzbPy-g-PEG in acetone- $d_{6}$ and (b) AzbPyBA solid compound in DMSO- $d_{6}$.

Table 1 Optical and thermal properties of AzbT ${ }^{a}$, AzbPyBA precursor and AzbPy-g-PEG macromonomer subsequently used in electrochemical copolymerization with Py monomer

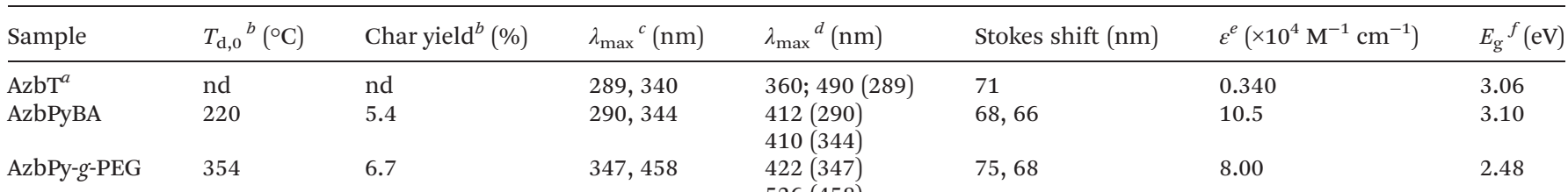

${ }^{a}$ Data from ref. $51 .{ }^{b}$ Initial decomposition temperatures and char yields as obtained by TGA. ${ }^{c}$ Maximum absorption bands obtained by UV-vis spectroscopy in DMSO. ${ }^{d}$ Fluorescence spectra were recorded in DMSO using the values of $\lambda_{\max }$ derived from UV-vis spectroscopy as $\lambda_{\mathrm{ex}}{ }^{e}$ The molar extinction coefficients $(\varepsilon)$ were calculated by applying the Lambert-Beer law at the values of $\lambda_{\max }$ obtained by UV-vis spectroscopy in the range of 340 to $347 \mathrm{~nm} .{ }^{f}$ Optical band gap estimated from the onset wavelength of optical absorption in solution $\left(E_{\mathrm{g}}=1240 / \lambda_{\text {onset }}\right)$ by UV-visible spectroscopy. nd - not determined.

shape (Fig. S2b $\dagger$ ) and a blue shift of $\lambda_{\max }$ (Table 1). The solutions of AzbPy- $g$-PEG are highly fluorescent at different concentrations under $365 \mathrm{~nm}$ of irradiation and also in daylight. This optoelectronic property has been attributed to the extended conjugation, which is induced through the self-assembly between neighboring molecules forming complementary hydrogen bonds.

The thermal properties of AzbPyBA and AzbPy- $g$-PEG macromonomer were evaluated by DSC. Fig. S3a† displays a broad exothermic peak in the range of $210{ }^{\circ} \mathrm{C}$ to $150{ }^{\circ} \mathrm{C}$ that was registered during the cooling cycle. This exothermic peak can be assigned to crystallization of the compound but also to other structural modifications that can take place due to the complex structural re-organization of this compound. In the second heating curve, only the first shallow transition corresponding to the beginning of the exothermic peak was revealed. This crystallization temperature $\left(206^{\circ} \mathrm{C}\right)$ was further confirmed in a second DSC experiment, which was conducted 
with a very low scan rate $\left(2{ }^{\circ} \mathrm{C} \mathrm{min}^{-1}\right)$ for the second heating cycle (Fig. S3b $\dagger$ ). On the other hand, the AzbPy-g-PEG macromonomer shows only the melting temperature $\left(54^{\circ} \mathrm{C}\right)$ and crystallization temperature $\left(28^{\circ} \mathrm{C}\right)$ corresponding to the PEG side chains (Fig. S3c $\dagger$ ). From the TGA analyses, it was demonstrated that the AzbPy-g-PEG precursor molecule, AzbPyBA, starts to decompose at around $220{ }^{\circ} \mathrm{C}$, whereas the macromonomer starts at $\sim 354{ }^{\circ} \mathrm{C}\left(T_{\mathrm{d}, 0}\right)$ with a maximum decomposition temperature of $405{ }^{\circ} \mathrm{C}\left(T_{\mathrm{d}, \max }\right)$ (Fig. S3d $\left.\dagger\right)$. The optical and thermal data are displayed in Table 1 , and a detailed discussion of these results is included in the ESI. $\dagger$

\section{Synthesis and characterization of P(Py-co-AzbPy- $g$-PEG) graft copolymers}

It is widely known that the oxidative chemical polymerization of PPy is limited by the tendency of this ICP to over-oxidize in oxygen-rich environments, and very low yields are usually obtained. Therefore, electrochemical synthesis has become the most versatile method for the generation of Py-containing polymers and copolymers; ${ }^{46,50-52,68,69}$ this procedure is also widely employed for the synthesis of other heterocyclic ICPs. ${ }^{70-73}$ However, the success of anodic polymerization processes, like those used in this work, largely depends on the mobility of the monomers that must reach the electrode surface, i.e. small, lightweight monomers move more quickly than heavy, bulky macromonomers. This may explain the unsuccessful homopolymerization of the AzbPy-g-PEG macromonomer, which due to its large size presents reduced mobility in organic solutions. This assumption is also sustained by the fact that other bis-pyrrole Schiff bases with similar structures but lower molecular weights were successfully homo-electropolymerized. ${ }^{50}$

In order to overcome the limitations associated with the low mobility of the macromonomer, $\mathrm{P}(\mathrm{Py}-\mathrm{co}-\mathrm{AzbPy}-\mathrm{g}$-PEG $)$ copolymers were prepared. Long polymerization times $(\theta=$ 300,500 and $1000 \mathrm{~s}$ ) were required to obtain homogenous films when the ratio of the comonomers in the feed (Py: AzbPy-g-PEG macromonomer) was $1: 1$. However, the real comonomer ratios in the hybrid material, as determined by FTIR, were approximately 521:1, 208:1, and 125:1 (Py: macromonomer) with $300 \mathrm{~s}, 500 \mathrm{~s}$ and $1000 \mathrm{~s}$ of electrochemical polymerization, respectively. According to the previous discussion, the excessively low content of the macromonomer units in the copolymer films is probably due to the lower mobility of the AzbPy- $g$-PEG macromonomer compared to the higher mobility of Py molecules. These results are in accordance with our previous studies with thiophene derivatives. ${ }^{56}$ As stated, the poor solubility of ICPs in organic solvents prevents the use of more accurate techniques, such as NMR and GPC, for precise evaluation of the comonomer ratio. Moreover, solid techniques such as mass spectrometry and solid ${ }^{13} \mathrm{C}-\mathrm{NMR}$ spectroscopy are also complicated to employ due to the charges present in the doped film.

Furthermore, bare PPy films were prepared using $\theta=300 \mathrm{~s}$ under identical experimental conditions for comparison. The SEM micrographs and AFM images displayed in Fig. 4a and b, c, respectively, reveal a cauliflower-like morphology for the $\mathrm{P}$ (Py-co-AzbPy-g-PEG) films independently of $\theta$, which is similar to the results for PPy. ${ }^{74,75}$ The film thickness $(L)$ of $\mathrm{P}$ (Py-co-AzbPy- $g$-PEG) increases with $\theta$, as was demonstrated by optical profilometry measurements. Thus, values of $L=1.4 \pm$ $0.4 \mathrm{~nm}, 2.6 \pm 0.5 \mathrm{~nm}$, and $4.1 \pm 0.5 \mathrm{~nm}$ were obtained for films generated using $\theta=300,500$, and $1000 \mathrm{~s}$, respectively. It can be assumed that the bent-shaped geometry and the presence of long PEG side chains in the AzbPy-g-PEG comonomer hinder the intermolecular chain packing of the copolymers, resulting in increased film thickness. Similarly, the roughness $\left(R_{\mathrm{q}}\right)$ increased from $91 \pm 5 \mathrm{~nm}$ to $123 \pm 11 \mathrm{~nm}$ when $\theta$ was increased from $300 \mathrm{~s}$ to $1000 \mathrm{~s}$. The $L$ and $R_{\mathrm{q}}$ values of the PPy films prepared using $\theta=300 \mathrm{~s}(2.2 \pm 0.1 \mathrm{~nm}$ and $112 \pm 9.9 \mathrm{~nm}$, respectively) are higher than those of the graft copolymer obtained using the same $\theta$ value. A possible explanation for these experimental findings is that the anodic polymerization of PPy is dominated by the crosslinks in the $\beta$ - and $\beta^{\prime}$-ring positions ${ }^{76}$ allowing non-regular growth of the polymer chains. The formation of multidirectional branches results in increments of both $L$ and $R_{\mathrm{q}}$ compared to other ICPs. ${ }^{75}$

As part of the surface characterization, the wettability of the copolymer was determined by measuring the water contact angle (WCA). As expected, the wettability of the copolymers increased with the roughness of the films and the content of hydrophilic grafted PEG chains. Thus, the values of WCA determined for the $\mathrm{P}(\mathrm{Py}-\mathrm{co}$-AzbPy-g-PEG) films obtained at $\theta=$ 300,500 and $1000 \mathrm{~s}$ were $71.0^{\circ} \pm 0.4^{\circ}, 62.6^{\circ} \pm 0.3^{\circ}$, and $48.5^{\circ} \pm$ $0.3^{\circ}$, respectively, demonstrating that the hydrophilicity increases with $\theta$. The WCA exhibited by PPy, $\left(58.9^{\circ} \pm 0.1^{\circ}\right)$, was intermediate between those obtained for the copolymers prepared using $\theta=300$ and $1000 \mathrm{~s}$, which is fully consistent with previous evidence of the influence of $R_{\mathrm{q}}$ on the wettability of PPy. ${ }^{77}$

The increased wettability observed for the $\mathrm{P}(\mathrm{Py}-\mathrm{co}-\mathrm{AzbPy}-\mathrm{g}$ PEG) films synthesized using the largest $\theta$ value can also be attributed to a potential higher content of PEG on the copolymer film surface. Due to the insolubility of the as-prepared films in deuterated solvents, unfortunately, determination of the ratios between the Py and AzbPy-g-PEG comonomers in the final copolymers using NMR spectroscopy was not possible. However, the presence of both PEG and AzbPy groups in the copolymers was assessed by comparing the FTIR spectra of the monomers with those of the final copolymers. Thus, the Py monomer shows remarkable bands centered at 3125 and $720 \mathrm{~cm}^{-1}$, which correspond to the $\mathrm{C}^{\alpha}-\mathrm{H}$ stretching and outof-plane vibration modes, respectively (Fig. 5a). The absence of these two absorption bands in the PPy homopolymer spectrum indicates that the hydrogen atoms at the $\mathrm{C}^{\alpha}$-position were removed during the polymerization process. The characteristic absorption bands of the PPy samples are the fundamental vibrations of the Py rings at 1525 and $1596 \mathrm{~cm}^{-1}$, the $=\mathrm{C}-\mathrm{N}$ stretching vibrations at 1464 and $1413 \mathrm{~cm}^{-1}$, the $=\mathrm{C}-\mathrm{H}$ inplane vibration at 1072 and $1040 \mathrm{~cm}^{-1}$, and the $\mathrm{N}-\mathrm{H}$ in-plane vibration at $1010 \mathrm{~cm}^{-1} .^{78}$ Although the Py monomer was distilled before use, the appearance of the $\mathrm{C}=\mathrm{O}$ band at 

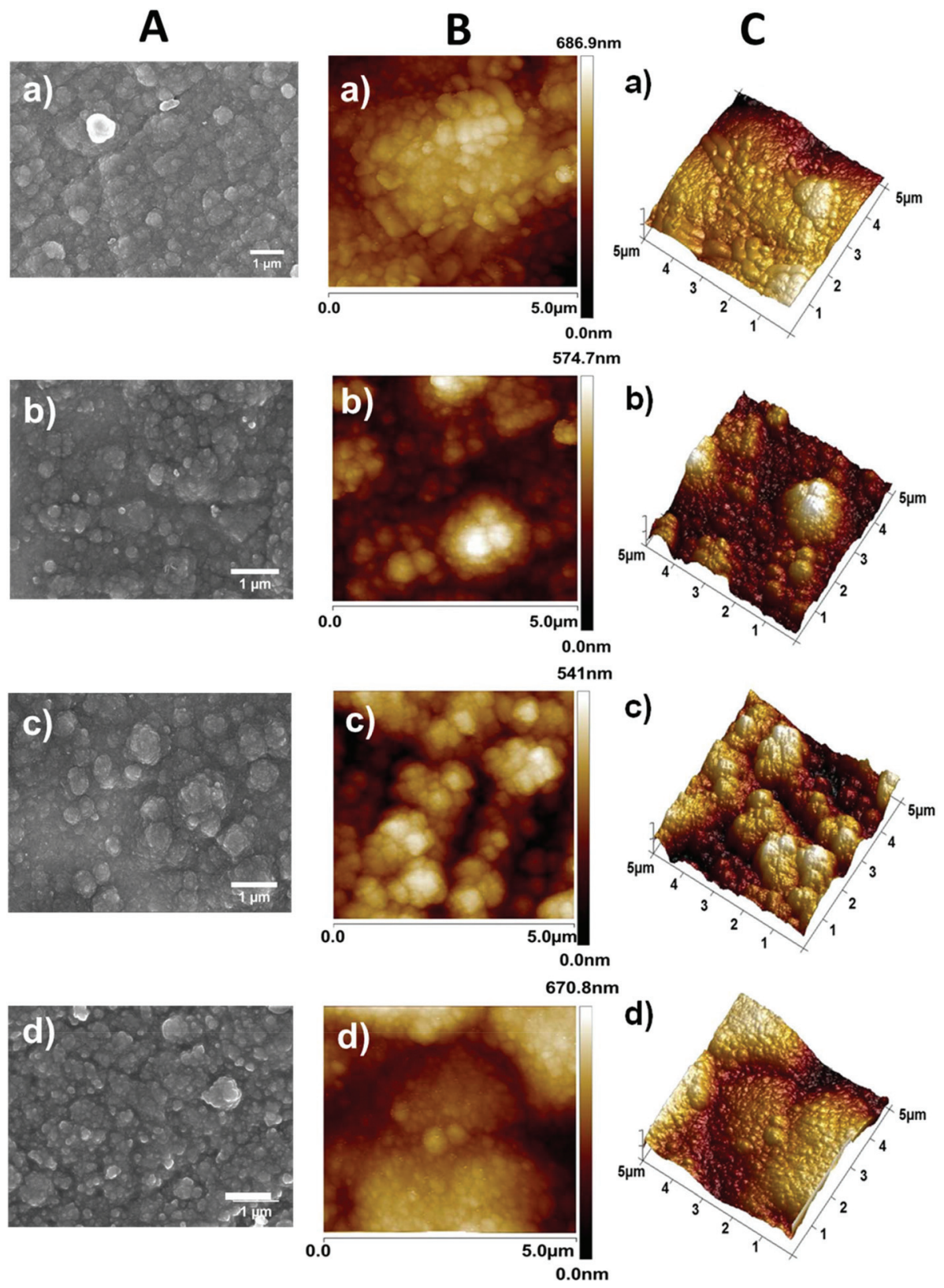

Fig. 4 (A) SEM micrographs, (B) 2D height AFM images $\left(5 \times 5 \mu \mathrm{m}^{2}\right)$ and (C) 3D topographic AFM images $\left(5 \times 5 \mu \mathrm{m}^{2}\right)$ of PPy obtained by CA using $\theta=$ $300 \mathrm{~s}$ (a) and P(Py-co-AzbPy-g-PEG) prepared by CA using $\theta=300,500$ and $1000 \mathrm{~s}$ (b, c and d, respectively). All samples for AFM analyses were supported on stainless steel electrodes.

$1714 \mathrm{~cm}^{-1}$ indicates some overoxidation after the electropolymerization in acetonitrile. ${ }^{68}$

After copolymerization, the most relevant bands of the PPy homopolymer remained unaltered, and new absorption bands from the PEG side chains appeared (Fig. 5b). The absorption band at $2921 \mathrm{~cm}^{-1}$ is usually attributed to the large methylene units $\left(-\mathrm{CH}_{2}-\right)$ from PEG chains; the bands at 1395 and $1446 \mathrm{~cm}^{-1}$ (not present in PPy) corroborate this assignment. The incorporation of AzbPy-g-PEG macromonomer into the copolymer formulation was particularly demonstrated when the time of electropolymerization increased from $300 \mathrm{~s}$ to 1000 s, due to the appearance of the sharp peak at $1727 \mathrm{~cm}^{-1}$, which is characteristic of ester linkages. Table $\mathrm{S} 1 \uparrow$ in summarizes the main absorption bands obtained for the monomers and polymers.

The structure of $\mathrm{P}(\mathrm{Py}-\mathrm{co}$-AzbPy- $g$-PEG) was also corroborated by Raman spectroscopy, as reflected in Fig. $5 \mathrm{c}$. The spectrum of PPy presents peaks at $1574 \mathrm{~cm}^{-1}$ and $1367 \mathrm{~cm}^{-1}$, which arise from the conjugated polymer backbone $(\mathrm{C}=\mathrm{C}$ stretching mode) and Py ring, respectively, and three bands at around $1090 \mathrm{~cm}^{-1}, 971 \mathrm{~cm}^{-1}$ and $935 \mathrm{~cm}^{-1}$ that are related to the inplane and out-of-plane deformations of $\mathrm{N}-\mathrm{H}$ and $\mathrm{C}-\mathrm{H}$ 
a)

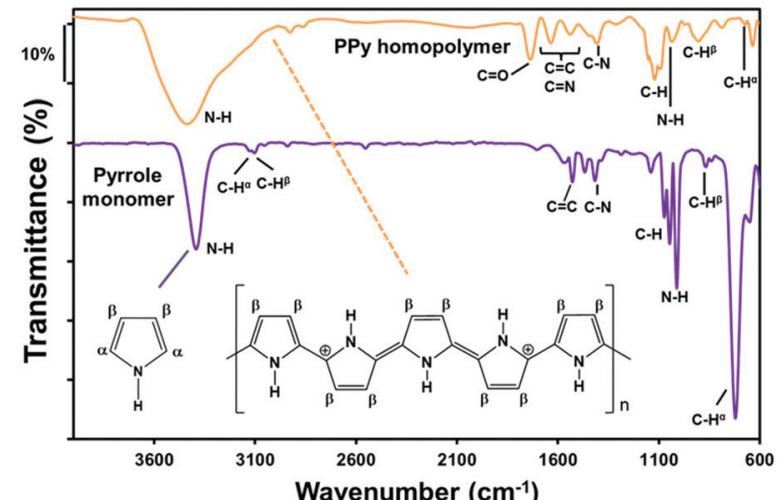

b)

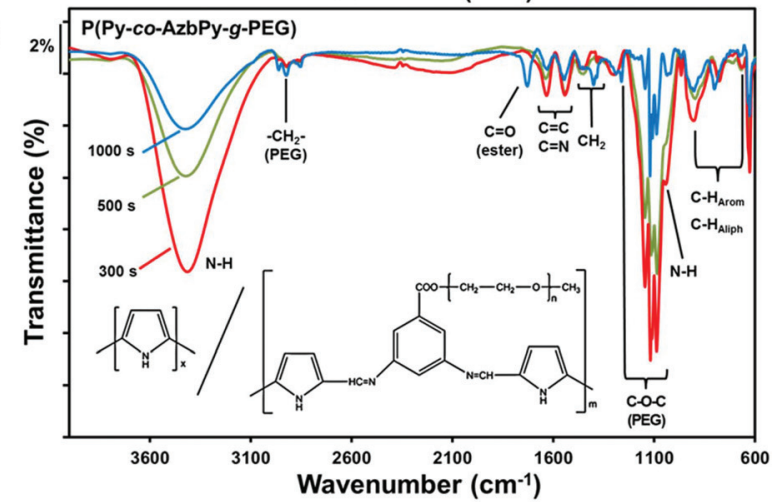

c)

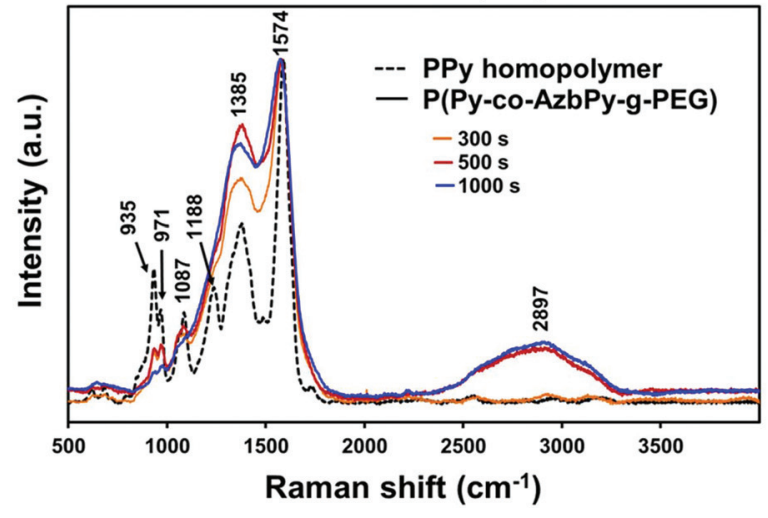

Fig. 5 FTIR spectra of: (a) Py monomer and PPy prepared by CA using $\theta=300 \mathrm{~s}$; and (b) P(Py-co-AzbPy-g-PEG) synthesized by CA using $\theta=$ 300,500 and 1000 s. (c) Raman spectra of P(Py-co-AzbPy-g-PEG) synthesized by CA using $\theta=300,500$ and $1000 \mathrm{~s}$. All films were generated on stainless steel electrodes as working electrodes.

groups. $^{79,80}$ The graft copolymers generated using $\theta=500$ and $1000 \mathrm{~s}$ also present broad bands at around 2890 to $2940 \mathrm{~cm}^{-1}$, which are attributed to the symmetric stretching vibrations of the methylene groups of the PEG chains. ${ }^{37,41}$

The grafting of hydrophilic, polar PEG chains to the conjugated polymer backbone is expected to affect its electrochemical activity and doping level. Control cyclic voltammograms of PPy deposited onto stainless steel showed the highest electroactivity with a voltammetric charge of $5.2 \times 10^{-2} \mathrm{C}$ (Fig. 6a). However, the control homopolymer displayed the highest loss of electrochemical activity (LEA $=48 \%$ ) after 50 consecutive cycles, which has been attributed to the dense
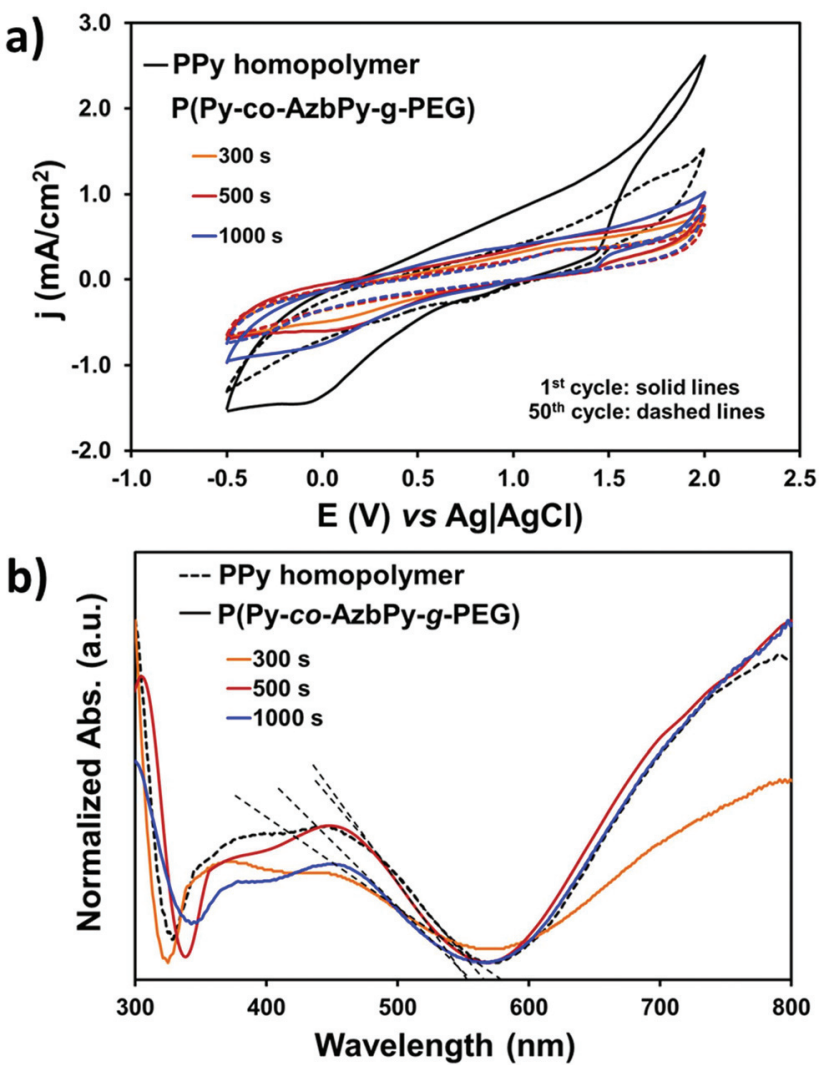

Fig. 6 (a) Cyclic voltammograms (scan rate: $50 \mathrm{mV} \mathrm{s}^{-1}$ ) recorded in a $0.1 \mathrm{M} \mathrm{LiClO}_{4}$ acetonitrile solution for PPy generated using $\theta=300 \mathrm{~s}$, and P(Py-co-AzbPy-g-PEG) copolymers obtained using $\theta=300,500$ and $1000 \mathrm{~s}: 2^{\text {nd }}$ cycle (solid lines) and $50^{\text {th }}$ cycle (dashed lines). (b) UV-vis spectra of the homopolymer and the copolymers freshly generated by CA onto ITO glass working electrodes. The dotted straight lines represent the best fit for the tangent of the band used to determine the $\varepsilon_{\mathrm{g}}$ for each system.

network of chemical crosslinks formed during the anodic polymerization process. $^{76}$ Thus, the formation of cross-links, which is also promoted by oxidation-reduction cycles, favors the organization of polymer chains in compact structures, precluding the diffusion of the dopant ions through the polymer/ electrolyte interface.

On the other hand, the electroactivity of the P(Py-co-AzbPy$g$-PEG) copolymers was less than half of that determined for the PPy homopolymer, even when $\theta=1000 \mathrm{~s}$. More specifically, the electrochemical activity experienced a decrease of $54 \%$ to $65 \%\left(2.8\right.$ to $3.4 \times 10^{-2} \mathrm{C}$ ) upon incorporation of the AzbPy- $g$-PEG macromonomer. This is consistent with the well-known detrimental effect on heterocyclic ring conjugation caused by electron-donating substituents. ${ }^{81}$ However, the LEA was significantly lower for the grafted copolymers than for the homopolymer after fifty oxidation-reduction cycles, demonstrating that the new semiconducting copolymers present good electrochemical stability when consecutive redox processes are applied.

The UV-vis spectra displayed in Fig. 6b indicate that the electronic properties of $\mathrm{P}(\mathrm{Py}-\mathrm{Co}-\mathrm{AzbPy}-\mathrm{g}$-PEG) and $\mathrm{PPy}$ are quite 
similar; no detrimental effects due to the presence of the electron-donating groups were detected. The UV-vis spectra show an absorption band in the visible region ( $\sim 300 \mathrm{~nm})$, which has been attributed to the $\pi-\pi^{*}$ transition in the tri-substituted benzene ring of AzbPy units. On the other hand, both the PPy and $\mathrm{P}(\mathrm{Py}-\mathrm{co}$-AzbPy- $g$-PEG $)$ copolymers present two broad absorption transitions starting at $320 \mathrm{~nm}$ and ending at $\sim 500 \mathrm{~nm}$, which have been associated with the polaron and bipolaron bands of the conductive quinoid and aromatic forms of the heterocycle conjugated rings and Schiff base linkages. ${ }^{51}$ Additionally, another high absorption phenomenon starts at $600 \mathrm{~nm}$, extending to values higher than $800 \mathrm{~nm}$. This corresponds to the interaction of the dopant molecules with the polymer chains, reflecting the complete oxidation of the latter. $^{82}$ This latter transition is practically identical for all copolymers, with the exception of $\mathrm{P}(\mathrm{Py}-\mathrm{Co}$-AzbPy- $g$-PEG) generated at $\theta=300 \mathrm{~s}$, which shows a slight reduction; this demonstrates that the doping levels are quite similar for all systems.

The band gap energy $\left(\varepsilon_{\mathrm{g}}\right)$ was calculated for each sample from the intersection of the dotted line, which corresponds to the tangent to the absorption band, and the absorption wavelength edge, as shown in Fig. 6b. The absorption maxima $\left(\lambda_{\text {max }}\right)$ and the $\varepsilon_{\mathrm{g}}$ values of the grafted copolymers and PPy are listed in Table S2. $\dagger$ The band gaps obtained for our systems are between 2.25 (PPy) and $2.30 \mathrm{eV}$ (P(Py-co-AzbPy- $g$ PEG) at $\theta=300 \mathrm{~s}$ ). These values are in accordance with those reported by Brooke et al. ${ }^{83}$ for films of PPy with PEG-PP-PEG triblock copolymers which were prepared by vapor phase deposition.

\section{Protein adsorption}

In addition to their material properties, several features of proteins, such as their molecular weights, structures, shapes and electrostatic charges, can influence their non-specific interactions with a material surface, in particular with ICPs. ${ }^{84}$

In the present study, bovine serum albumin (BSA) and lysozyme (Lyz) were used as model proteins for adsorption experiments. These proteins, which contain free cysteine residues (which can be exploited in conjugation studies or in chemical adsorption with other substances), have considerably different molecular weights (66.5 kDa for BSA and $14.3 \mathrm{kDa}$ for Lyz). Furthermore, Lyz exhibits an ellipsoidal shape as a quaternary structure, in which both ordered (30\% $\alpha$-helix, 27\% $\beta$-turn and $13 \% \quad \beta$-sheet secondary structures) and unordered (30\%) regions coexist; ${ }^{85}$ meanwhile, the "heart"-shaped ${ }^{86}$ secondary structure of BSA is predominantly $\alpha$-helical, with the remaining polypeptide occurring in turns and extended or flexible regions (i.e. with no $\beta$-sheets). ${ }^{87}$

The adsorptions of BSA and Lyz onto the surface of steel, PPy and P(Py-Co-AzbPy-g-PEG) generated at $\theta=1000 \mathrm{~s}$ are shown in Fig. 7a. As can be seen, the adsorptions of both BSA and Lyz were significantly higher on the graft copolymer film than on the PPy homopolymer. This has been attributed to the presence of PEG groups, which facilitates the interaction with the hydrophilic residues of the proteins [Referee \#2].

In contrast, the $\mathrm{N}-\mathrm{H}$ groups of $\mathrm{PPy}$ are expected to be sterically hindered; thus, they cannot readily interact with the polar residues of the proteins. Indeed, the adsorption of pro-
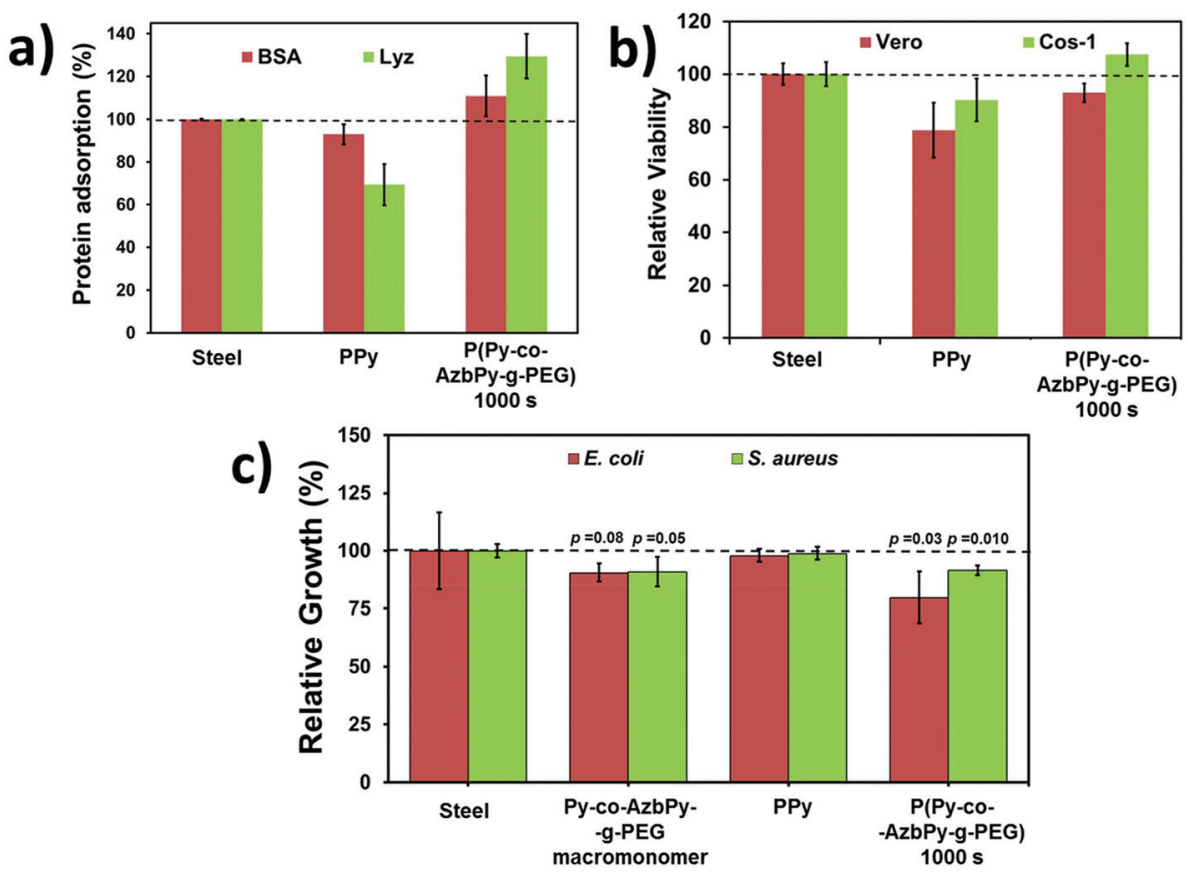

Fig. 7 For PPy and P(Py-Co-AzbPy-g-PEG) obtained using $\theta=1000$ s: (a) protein adsorption using BSA and Lyz; (b) cytotoxicity using Vero and COS-1 cultured cells; and (c) antimicrobial response using Escherichia coli (E. coli) and Staphylococcus aureus (S. aureus). The antimicrobial response of the AzbPy-g-PEG macromonomer is also evaluated in (c). Steel was used as a control substrate in all cases. Statistical analyses were performed with a confidence level of $95 \%(p<0.05)$ using Student's $T$-test. 
teins on PPy is even lower than that observed on the steel substrate. These results are fully consistent with the hydrophilicity ranking determined by WCA measurements (i.e. $48.5^{\circ} \pm 0.3^{\circ}$ and $58.9^{\circ} \pm 0.1^{\circ}$ for $\mathrm{P}(\mathrm{Py}-\mathrm{Co}$-AzbPy- $g$-PEG) and PPy, respectively). Also, the low protein adsorption observed for PPy in comparison with $\mathrm{P}(\mathrm{Py}-\mathrm{co}-\mathrm{AzbPy}-\mathrm{g}$-PEG) indicates that in the latter, the PEG groups play the most important role in the interactions with Lyz and BSA.

On the other hand, $\mathrm{P}(\mathrm{Py}-\mathrm{co}$-AzbPy- $g$-PEG) exhibits higher affinity for Lyz than for BSA, even though the amount of charged residues is significantly higher in the latter than in the former. This result indicates the preference of the copolymer towards small ellipsoid proteins rather than bulky proteins organized in helical bundle domains, in which the attractive electrostatic interactions induced by many charged residues are shielded by residues located at neighboring secondary motifs.

On the other hand, comparison with previous results indicates that $\mathrm{P}(\mathrm{Py}-\mathrm{co}$-AzbPy-g-PEG) exhibits higher affinity towards proteins than $\mathrm{PTh}_{5}-g-\mathrm{PEG}_{2000}$ and $\mathrm{PTh}_{5}-g-\mathrm{PEG}_{1000} \cdot{ }^{3}$ More specifically, the adsorptions of BSA with respect to steel (100\%) were reported to be $113 \%$ and $106 \%$ for $\mathrm{PTh}_{5}-g-\mathrm{PEG}_{2000}$ and $\mathrm{PTh}_{5}-\mathrm{g}-\mathrm{PEG}_{1000}$, respectively, while the adsorption of collagen was $\sim 100 \%$ for these copolymers. ${ }^{3}$ These values are lower than those achieved by $\mathrm{P}(\mathrm{Py}-\mathrm{Co}-\mathrm{AzbPy}-\mathrm{g}$-PEG) for BSA (118\%) and, especially, Lyz (137\%) (Fig. 7a).

\section{In vitro cytotoxicity and antimicrobial activity}

The potential cytotoxicities of P(Py-co-AzbPy- $g$-PEG), PPy and steel were evaluated using the MTT assay for cell viability determination, which was conducted after $72 \mathrm{~h}$ of culturing Vero and COS-1 cells. No evidence of cytotoxicity was found for PPy or P(Py-co-AzbPy-g-PEG). However, differences in the number of cells adhering to the films were detected (Fig. 7b); the cell viabilities were $10 \%$ to $20 \%$ higher for $\mathrm{P}(\mathrm{Py}-\mathrm{Co}-\mathrm{AzbPy}-\mathrm{g}$ PEG) than for PPy. This behaviour has been attributed to the well-known biocompatibility of grafted PEG chains, which improves the cellular adhesion behaviour of the semiconducting polymer backbone. The influences of the steel, PPy and $\mathrm{P}(\mathrm{Py}-\mathrm{co}$-AzbPy- $g$-PEG) films on Cos-1 cell morphology were qualitatively evaluated by SEM (Fig. S4 $\dagger$ ).

On the other hand, it has been reported that materials with azomethine exhibit antimicrobial activity. ${ }^{8,89}$ The antimicrobial responses of PPy, P(Py-co-AzbPy- $g$-PEG) and AzbPy- $g$ PEG are compared in Fig. 7c. As can be seen, both the macromonomer and the graft copolymer exhibit some antibacterial response against Escherichia coli and Staphylococcus aureus, while the antimicrobial activities of steel and PPy are null. Previous studies indicated that the response of PPy to bacteria strongly depends on the dopant and redox state of the ICP and the characteristics of the bacterial strain. ${ }^{58,90,91}$

Although this effect may be due to the action of the Schiff base moiety, other explanations are also possible because the concentration at which the antibacterial test was performed $(4.3 \mathrm{mM})$ is in approximately the same range as that $(6 \mathrm{mM})$ in which "T-shaped" septithiophene oligomers grafted with
$\mathrm{PEG}_{2000}$ formed self-assembled "core-shell" type micellar structures. ${ }^{92}$ In that case, the access to the Schiff base groups was hindered by the PEG shell of the micelles; therefore, the observed inhibitory effect may be due to the ability of PEG to complex metal cations, particularly $\mathrm{Ca}^{2+} \cdot{ }^{93}$ Thus, displacement of $\mathrm{Ca}^{2+}$ ions from the outer membrane of bacterial cells toward AzbPy-g-PEG self-assembled micelles can disrupt the integrity of the bacterial cells, ${ }^{94}$ resulting in inhibition of their growth.

These results, combined with the observed cell viability, suggest that $\mathrm{P}(\mathrm{Py}-\mathrm{co}-\mathrm{AzbPy}-\mathrm{g}$-PEG$)$ is a promising candidate for the development of biomedical applications, such as implantable integrated devices for release of neurotransmitters under real-time monitoring. In the next section, we explore the potential of $\mathrm{P}(\mathrm{Py}-\mathrm{co}-\mathrm{AzbPy}-\mathrm{g}$-PEG) for the sensitive detection of serotonin (5-hydroxytryptamine), which is a monoamine neurotransmitter biochemically derived from tryptophan that is primarily found in blood platelets and the central nervous systems of animals and humans.

\section{Specific electrochemical detection capability of serotonin}

Py is a well-known $\pi$-conjugated building block that is typically employed for engineering planar anionic receptors, acting as both a metal-coordination ligand ( $\mathrm{N}$ sites) and a hydrogenbonding donor (N-H moiety).$^{95}$ Additionally, the complementarity between the electron-donor and electron-acceptor behavior of the Py ring and the serotonin neurotransmitter, respectively, is beneficial for the design of sensitive sensors.

Fig. 8a and b compare the differential pulse voltammograms recorded in solutions with different concentrations of serotonin (from 0 to $20 \mu \mathrm{M}$ ) in $0.1 \mathrm{M}$ PBS ( $\mathrm{pH}$ 7.4) for PPy $(\theta=300 \mathrm{~s})$ and $\mathrm{P}(\mathrm{Py}-\mathrm{co}-\mathrm{AzbPy}-\mathrm{g}$-PEG) $(\theta=1000 \mathrm{~s})$, respectively. As can be seen, both polymers are able to catalyze the oxidation of serotonin molecules in a low potential range. Although the anodic peak current decreases with decreasing serotonin concentration, the position of the peak potential in the copolymer film remains almost constant at 0.29 to $0.31 \mathrm{~V}$ for all the tested concentrations. In a very recent study, Cristea and co-workers ${ }^{96}$ prepared detectors of serotonin using electrochemically generated PPy nanoparticles which were decorated with catalytic gold nanoparticles. However, this $\mathrm{P}(\mathrm{Py}-\mathrm{co}-\mathrm{AzbPy}-$ $g$-PEG) sensor presents important advantages with respect to the latter, such as the facile preparation of polymeric films without the need of activation with metal nanoparticles.

The serotonin detection limits of the PPy and $\mathrm{P}\left(\mathrm{Py}-\mathrm{Co}^{-}\right.$ AzbPy-g-PEG) sensors were derived from the variations of the maximum peak current density $(j)$ against the serotonin concentration, as determined by DPV. The resulting calibration curves (Fig. 8c and d) show linear behavior in the whole interval of the examined serotonin concentrations. The detection limit is expressed as $3.3 \cdot \sigma / S$, where $\sigma$ and $S$ are the standard deviation of the response and the slope of the calibration curve for serotonin concentrations ranging from 0.5 to $20 \mu \mathrm{M}$; the limits are 0.04 and $0.07 \mu \mathrm{M}$ for PPy and P(Py-co-AzbPy- $g$ PEG), respectively.

In summary, the structural characteristics of $\mathrm{P}(\mathrm{Py}-\mathrm{co}-\mathrm{AzbPy}-$ $g$-PEG) are suitable for complex biomedical applications in 

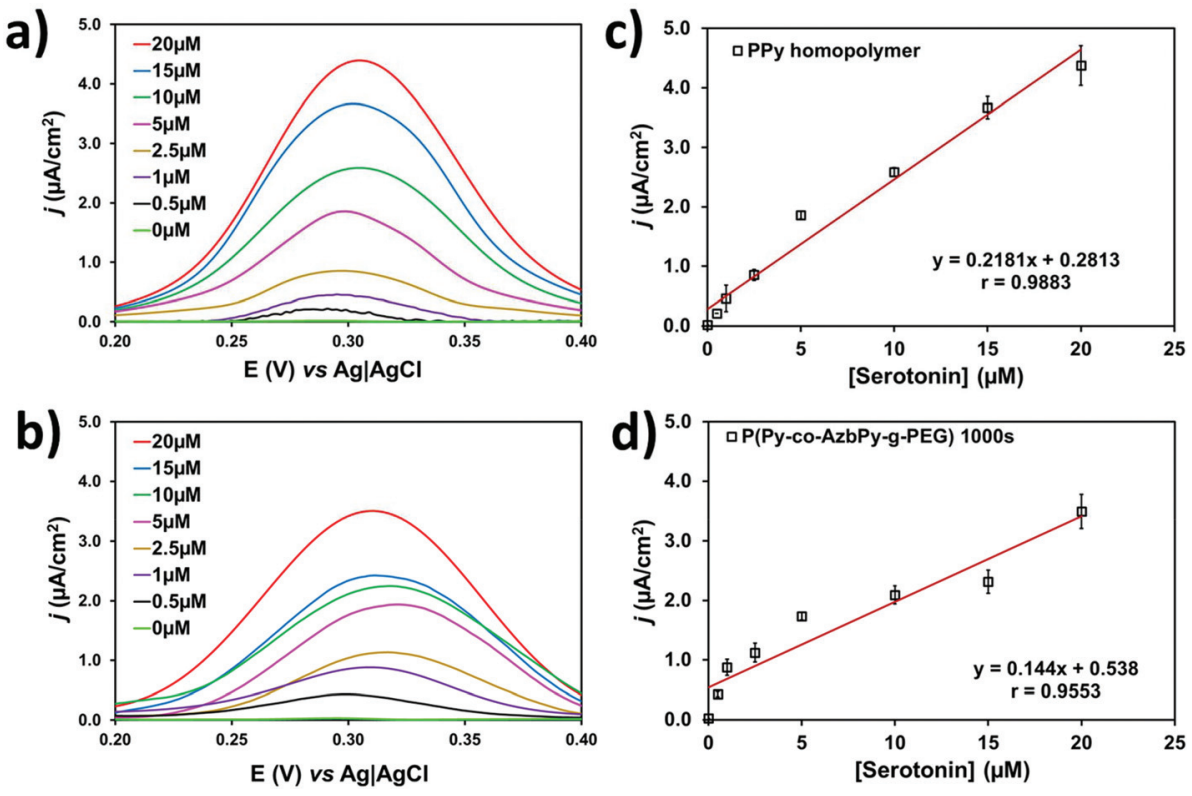

Fig. 8 Differential pulse voltammograms in $0.1 \mathrm{M} \mathrm{PBS} \mathrm{(pH} \mathrm{7.2)} \mathrm{with} \mathrm{serotonin} \mathrm{concentrations} \mathrm{ranging} \mathrm{from} 0.5$ to $20 \mu \mathrm{M}$ for: (a) PPy and (b) P(Pyco-AzbPy-g-PEG) generated on glassy carbon electrode using $\theta=300$ and $1000 \mathrm{~s}$, respectively. Calibration curves for serotonin detection in a concentration range from 0 to $20 \mu \mathrm{M}$ for (c) PPy and (d) P(Py-co-AzbPy-g-PEG).

which several functions must be fulfilled simultaneously, such as implantable electrodes to monitor the level of serotonin. This type of electrode requires not only a high detection capacity, such as that imparted by the conjugated main chain of the copolymer, but also must present biocompatibility, provided by the PEG grafted chains, to facilitate its integration in the body, and antimicrobial activity, induced by the synergistic combination of the chemical and architectural peculiarities of the copolymer, to prevent infections after implantation. Additionally, the modified electrode obtained in this study is easy to prepare compared to other hybrid materials being developed, such as those combining metallic nanoparticles and carbon nanotubes ${ }^{97}$ or complex electrodes. ${ }^{98-100}$

\section{Conclusions}

In this work, chemically and architecturally complex copolymers containing Py ring and Schiff base functionalities in their backbones and PEG as grafted chains have been engineered and characterized. The properties of the obtained $\mathrm{P}(\mathrm{Py}-$ co-AzbPy- $g$-PEG) have been compared with those of bare PPy homopolymer and other related copolymers from which they were inspired, such as (i) $\mathrm{P}\left(\mathrm{AzbT}-\mathrm{co}-\mathrm{Th}_{3}\right)$, in which an azomethine-containing Schiff base was copolymerized with $\mathrm{Th}_{3}$; and (ii) PTh-g-PEG, a family of grafted copolymers without Schiff base functionalities in which PEG side chains were anchored to the PTh backbone. The antimicrobial activity of the novel graft copolymer was enhanced compared to that of previously studied copolymers.

Our results show that this synthetic approach, which sequentially combines the "macromonomer technique" with electrochemical polymerization, can be a useful alternative that enables the combination of otherwise incompatible building blocks to obtain multifunctional materials capable of encompassing diverse applications.

\section{Conflicts of interest}

There are no conflicts to declare.

\section{Acknowledgements}

This work was supported by MINECO (MAT2015-69367-R) and the Agència de Gestió d'Ajuts Universitaris i de Recerca (2017SGR359). Support for the research by C. A. was received through the prize "ICREA Academia 2015" for excellence in research, funded by the Generalitat de Catalunya (CataloniaSpain). B. G. M. is thankful to CONACYT agency for their financial support through a postgraduate scholarship (328467 CVU 621314). The authors are grateful to Prof. G. Lisa from the Faculty of Chemical Engineering and Environmental Protection of "Gheorghe Asachi" Technical University, Iasi, Romania for TGA and DSC measurements. The Romanian authors dedicate this paper to Professor Bogdan C. Simionescu on the occasion of his $70^{\text {th }}$ birthday.

\section{References}

1 M. Rehahn and A. D. Schluter, Polymer, 1989, 30, 10541059. 
2 W. A. Goedel, N. S. Somanathan, V. Ekelman and G. Wegner, Makromol. Chem., 1992, 193, 1195-1206.

3 A.-D. Bendrea, G. Fabregat, L. Cianga, F. Estrany, L. J. del Valle, I. Cianga and C. Alemán, Polym. Chem., 2013, 4, 2709-2723.

4 T. F. Otero, Electrochim. Acta, 2016, 212, 440-457.

5 M. E. Abdelhamid, A. P. O'Mullane and G. A. Snook, RSC Adv., 2015, 5, 11611-11626.

6 T. F. Otero and J. G. Martinez, J. Mater. Chem. B, 2016, 4, 2069-2085.

7 Y.-Z. Long, M.-M. Li, C. Gu, M. Wan, J.-L. Duvail, Z. Liu and Z. Fan, Prog. Polym. Sci., 2011, 36, 1415-1442.

8 T.-H. Le, Y. Kim and H. Yoon, Polymers, 2017, 9, 150.

9 S. Soylemez, S. O. Hacioglu, M. Kesik, H. Unay, A. Cirpan and L. Toppare, ACS Appl. Mater. Interfaces, 2014, 6, 18290-18300.

10 G. Fabregat, E. Córdova-Mateo, E. Armelin, O. Bertran and C. Alemán, J. Phys. Chem. C, 2011, 115, 14933-14941.

11 G. Fabregat, E. Armelin and C. Alemán, J. Phys. Chem. B, 2014, 118, 4669-4682.

12 L. D. Sappia, E. Piccinini, W. Marmisollé, N. Santilli, E. Maza, S. Moya, F. Battaglini, R. E. Madrid and O. Azzaroni, Adv. Mater. Interfaces, 2017, 4, 1700502.

13 N. Aydemir, J. Malmström and J. Travas-Sejdic, Phys. Chem. Chem. Phys., 2016, 18, 8264-8277.

14 S. B. Thourson and C. K. Payne, Sci. Rep., 2017, 7, 10402.

15 T. F. Otero and J. G. Martinez, Prog. Polym. Sci., 2015, 44, 62-78.

16 C. Plesse, F. Vidal, D. Teyssié and C. Chevrot, Chem. Commun., 2010, 46, 2910.

17 A. Puiggalí-Jou, P. Micheletti, F. Estrany, L. J. del Valle and C. Alemán, Adv. Healthcare Mater., 2017, 6, 1700453.

18 D. Samanta, N. Hosseini-Nassab and R. N. Zare, Nanoscale, 2016, 8, 9310-9317.

19 D. Samanta, J. L. Meiser and R. N. Zare, Nanoscale, 2015, 7, 9497-9504.

20 Y. Wang, Y. Xiao and R. Tang, Chem. - Eur. J., 2014, 20, 11826-11834.

21 D. Park, Y. Cho, S.-H. Goh and Y. Choi, Chem. Commun., 2014, 50, 15014-15017.

22 C. Zhong, D. Ke, L. Wang, Y. Lu and L. Wang, Electrochem. Commun., 2017, 79, 59-62.

23 J. Goding, A. Gilmour, P. Martens, L. Poole-Warren and R. Green, Adv. Healthcare Mater., 2017, 6, 1601177.

24 C. Yu, C. Wang, X. Liu, X. Jia, S. Naficy, K. Shu, M. Forsyth and G. G. Wallace, Adv. Mater., 2016, 28, 9349-9355.

25 A. Jonsson, S. Inal, L. Uguz, A. J. Williamson, L. Kergoat, J. Rivnay, D. Khodagholy, M. Berggren, C. Bernard, G. G. Malliaras and D. T. Simon, Proc. Natl. Acad. Sci. U. S. A., 2016, 113, 9440-9445.

26 R. Green and M. R. Abidian, Adv. Mater., 2015, 27, 7620-7637.

27 B. Guo and P. X. Ma, Biomacromolecules, 2018, 19, 1764-1782.

28 Y. Wu, B. Guo and P. X. Ma, ACS Macro Lett., 2014, 3, 1145-1150.

29 R. Dong, X. Zhao, B. Guo and P. X. Ma, ACS Appl. Mater. Interfaces, 2016, 8, 17138-17150.
30 M. Xie, L. Wang, J. Ge, B. Guo and P. X. Ma, ACS Appl. Mater. Interfaces, 2015, 7, 6772-6781.

31 X. Zhao, B. Guo and P. X. Ma, J. Mater. Chem. B, 2015, 3, 8459-8468.

32 M. Wang, S. Zou, G. Guerin, L. Shen, K. Deng, M. Jones, G. C. Walker, G. D. Scholes and M. A. Winnik, Macromolecules, 2008, 41, 6993-7002.

33 B. G. Molina, A. D. Bendrea, L. Cianga, E. Armelin, L. J. del Valle, I. Cianga and C. Alemán, Polym. Chem., 2017, 8, 6112-6122.

34 J. Zhang, J. Lei, R. Pan, Y. Xue and H. Ju, Biosens. Bioelectron., 2010, 26, 371-376.

35 H. Zhao, B. Zhu, S.-C. Luo, H.-A. Lin, A. Nakao, Y. Yamashita and H. Yu, ACS Appl. Mater. Interfaces, 2013, 5, 4536-4543.

36 M. Waugaman, B. Sannigrahi, P. McGeady and I. M. Khan, Eur. Polym. J., 2007, 39, 1405-1412.

37 A.-D. Bendrea, G. Fabregat, L. Cianga, F. Estrany, L. J. del Valle, I. Cianga and C. Alemán, Polym. Chem., 2013, 4, 2709-2723.

38 A.-D. Bendrea, G. Fabregat, J. Torras, S. Maione, L. Cianga, L. J. del Valle, I. Cianga and C. Alemán, J. Mater. Chem. B, 2013, 1, 4135-4145.

39 A.-D. Bendrea, L. Cianga, E. Hitruc, I. Titorencu and I. Cianga, Mater. Plast., 2013, 50, 71-78.

40 S. Maione, G. Fabregat, L. J. del Valle, A.-D. Bendrea, L. Cianga, I. Cianga, F. Estrany and C. Alemán, J. Polym. Sci., Part B: Polym. Phys., 2015, 53, 239-252.

41 L. Cianga, A.-D. Bendrea, N. Fifere, L. E. Nita, F. Doroftei, D. Ag, M. Seleci, S. Timur and I. Cianga, RSC Adv., 2014, 4, 56385-56405.

42 A. Iwan and D. Sek, Prog. Polym. Sci., 2008, 33, 289-345.

43 C. I. Simionescu, I. Cianga, M. Ivanoiu, A. Duca, I. Cocarla and M. Grigoras, Eur. Polym. J., 1999, 35, 587-599.

44 M. Grucela-Zajac, K. Bijak, E. Zaleckas, S. Grigalevicius, M. Wiacek, H. Janeczek and E. Schab-Balcerzak, Opt. Mater, 2014, 37, 543-551.

45 A. Bolduc, S. Barik, M. R. Lenze, K. Meerholz and W. G. Skene, J. Mater. Chem. A, 2014, 2, 15620-15626.

46 S. Tarkuc, E. Sahin, L. Toppare, D. Colak, I. Cianga and Y. Yagci, Polymer, 2006, 47, 2001-2009.

47 D. Isik, C. Santato, S. Barik and W. G. Skene, Org. Electron., 2012, 13, 3022-3031.

48 C. Mallet, M. Le Borgne, M. Starck and W. G. Skene, Polym. Chem., 2013, 4, 250-254.

49 C. I. Simionescu, M. Grigoras, I. Cianga, I. Diaconu and A. Farcas, Polym. Bull., 1994, 32, 257-264.

50 C. I. Simionescu, M. Grovu-Ivanoiu, M. Grigoras and I. Cianga, Angew. Makromol. Chem., 1994, 221, 103-115.

51 C. I. Simionescu, M. Grovu-Ivanoiu, I. Cianga, M. Grigoras, A. Duca and I. Cocarla, Angew. Makromol. Chem., 1996, 239, 1-12.

52 C. I. Simionescu, I. Cianga, M. Ivanoiu, A. Airinei, M. Grigoras and I. Radu, Eur. Polym. J., 1998, 35, 1895-1905.

53 D. Colak, I. Cianga, A. E. Muftuoglu and Y. Yagci, J. Polym. Sci., Part A: Polym. Chem., 2006, 44, 727-743. 
54 A. Gul, Z. Akhter, M. Siddiq, S. Sarfraz and B. Mirza, Macromolecules, 2013, 46, 2800-2807.

55 L. Marin, D. Ailincai, M. Calin, D. Stan, C. A. Constantinescu, L. Ursu, F. Doroftei, M. Pinteala, B. C. Simionescu and M. Barboiu, ACS Biomater. Sci. Eng., 2016, 2, 104-111.

56 M. M. Pérez-Madrigal, L. Cianga, L. J. del Valle, I. Cianga and C. Alemán, Polym. Chem., 2015, 6, 4319-4335.

57 F. A. G. da Silva Jr., J. C. Queiroz, E. R. Macedo, A. W. C. Fernandes, N. B. Freire, M. M. da Costa and H. P. de Oliveira, Mater. Sci. Eng., C, 2016, 62, 317-322.

58 M. Golabi, A. P. F. Turner and E. W. H. Jager, Macromol. Chem. Phys., 2016, 217, 1128-1135.

59 X. Qu and Z. Yang, Chem. - Asian J., 2016, 11, 2633-2641.

60 A. Giovannitti, I. P. Maria, D. Hanifi, M. J. Donahue, D. Bryant, K. J. Barth, B. E. Makdah, A. Savva, D. Moia, M. Zetek, P. R. F. Barnes, O. G. Reid, S. Inal, G. Rumbles, G. G. Malliaras, J. Nelson, J. Rivnay and I. McCulloch, Chem. Mater., 2018, 30, 2945-2953.

61 M. S. Ganewatta, M. A. Rahman, L. Mercado, T. Shokfai, A. W. Decho, T. M. Reineke and C. Tang, Bioact. Mat., 2018, 3, 186-193, DOI: 10.1016/j.bioactmat.2018.02.001.

62 J. L. Kerstetter and W. Gramlich, J. Mater. Chem. B, 2014, 2, 8043-8052.

63 L. Arnt, K. Nusslein and G. N. Tew, J. Polym. Sci., Part A: Polym. Chem., 2004, 42, 3860-3864.

64 D. G. Colak, I. Cianga, L. Cianga and Y. Yagci, Des. Monomers Polym., 2016, 19, 508-534.

65 The values for Hansen solubility parameters, $\delta_{\mathrm{t}}$ (in $\mathrm{MPa}^{1 /}$ ${ }^{2}$ ) of DMSO and acetone were taken by accessing the address http://www.accudynetest.com, while that for PEG was considered from K. Adamska, A. Voelkel and A. Berlinska, J. Pharm. Biomed. Anal., 2016, 127, 202-206.

66 W. G. Herkstroeter, J. Am. Chem. Soc., 1973, 95, 86868691.

67 P. Douglas, C. Couture, D. Clarke, D. Reed, I. H. Sadler and T. Wear, J. Chem. Soc., Perkin Trans. 2, 1994, 12951298.

68 B. Teixeira-Dias, C. Alemán, F. Estrany, D. S. Azambuja and E. Armelin, Electrochim. Acta, 2011, 56, 5836-5843.

69 D. Aradilla, F. Estrany, E. Armelin, R. Oliver, J. I. Iribarren and C. Alemán, Macromol. Chem. Phys., 2010, 211, 16631672.

70 G. Fabregat, E. Córdova-Mateo, E. Armelin, O. Bertran and C. Alemán, J. Phys. Chem. C, 2011, 115, 14933-14941.

71 C. Ocampo, E. Armelin, F. Estrany, L. J. Del Valle, R. Oliver, F. Sépulcre and C. Alemán, Macromol. Mater. Eng., 2007, 292, 85-94.

72 C. Alemán, F. Estrany, E. Armelin, R. Oliver and J. Casanovas, Polymer, 2007, 48, 6162-6169.

73 D. Aradilla, F. Estrany, E. Armelin and C. Alemán, Thin Solid Films, 2012, 520, 4402-4409.

74 F. Estrany, D. Aradilla, R. Oliver, E. Armelin and C. Alemán, Eur. Polym. J., 2008, 44, 1323-1330.

75 D. Aradilla, F. Estrany, E. Armelin and C. Alemán, Thin Solid Films, 2010, 518, 4203-4210.
76 C. Alemán, J. Casanovas, J. Torras, O. Bertrán, E. Armelin, R. Oliver and F. Estrany, Polymer, 2008, 49, 1066-1075.

77 K. S. Teh, Y. Takahashi, Z. Yao and Y. W. Lu, Sens. Actuators, A, 2009, 155, 113-119.

78 M. Omastova, M. Trchova, J. Kovarova and J. Stejskal, Synth. Met., 2003, 138, 447-445.

79 V. Chandra and K. S. Kim, Chem. Commun., 2011, 47, 3942-3944.

80 X. Fan, Z. Yang and N. He, RSC Adv., 2015, 5, 1509615102.

81 A. R. Murphy, J. Liu, C. Luscombe, D. Kavulak, J. M. J. Fréchet, R. J. Kline and M. D. McGehee, Chem. Mater., 2005, 17, 4892-4899.

82 J. Arjomandi, A.-U.-H. A. Shah, S. Bilal, H. Van Hoang and R. Holze, Spectrochim. Acta, Part A, 2011, 78, 1-6.

83 R. Brooke, D. Evans, P. Hojati-Talemi, P. Murphy and M. Fabretto, Eur. Polym. J., 2014, 51, 28-36.

84 M. J. Higgins, P. J. Molino, Z. Yue and G. G. Wallace, Chem. Mater., 2012, 24, 828-839.

85 M. S. Weiss, G. J. Palm and R. Hilgenfeld, Acta Crystallogr., Sect. D: Biol. Crystallogr., 2000, 56, 952-958.

86 M. L. Ferrer, R. Duchowicz, B. Carrasco, J. G. de la Torre and A. U. Acuna, Biophys. J., 2001, 80, 2422-2430.

87 K. A. Majorek, P. J. Porebski, A. Dayal, M. D. Zimmerman, K. Jablonska, A. J. Stewart, M. Chruszcz and W. Minor, Mol. Immunol., 2012, 52, 174-182.

88 N. Yilmaz Baran, M. Karakişla, H. Ö. Demir and M. Saçak, J. Mol. Struct., 2016, 1123, 153-161.

89 C. M. Da Silva, D. L. Da Silva, L. V. Modolo, R. B. Alves, M. A. De Resende, C. V. B. Martins and A. De Fátima, J. Adv. Res., 2011, 2, 1-8.

90 M. Golabi, A. P. F. Turner and E. W. H. Jager, Sens. Actuators, B, 2016, 222, 839-848.

91 W. Zhou, L. Lu, D. Chen, Z. Wang, J. Zhai, R. Wang, G. Tan, J. Mao, P. Yu and C. Ning, J. Mater. Chem. B, 2018, 6, 3128-3135.

92 A.-D. Bendrea, L. Cianga, E. G. Hitruc and I. Cianga, Int. J. Polym. Anal. Charact., 2013, 18, 189-198.

93 M. Pannuzzo, D. H. De Jong, A. Raudino and S. J. Marrink, J. Chem. Phys., 2014, 140, 124905, DOI: 10.1063/1.4869176.

94 L. A. Clifton, M. W. A. Skoda, A. P. Le Brun, F. Ciesielski, I. Kuzmenko, S. A. Holt and J. H. Lakey, Langmuir, 2015, 31, 404-412.

$95 \mathrm{Q}$. Li, Intelligent stimuli-responsive materials: from welldefined nanostructures to applications, John Wiley \& Sons, ch. 12, 2013.

96 M. Tertiş, A. Cernat, D. Lacatiş, A. Florea, D. Bogdan, M. Suciu, R. Săndulescu and C. Cristea, Electrochem. Commun., 2017, 75, 43-47.

97 I. Cesarino, H. V. Galesco and S. A. S. Machado, Mater. Sci. Eng., C, 2014, 40, 49-54.

98 X. Jiang and X. Lin, Anal. Chim. Acta, 2005, 537, 145-151.

$99 \mathrm{~J} . \mathrm{Li}$ and X. Lin, Sens. Actuators, B, 2007, 124, 486-493.

100 S. Sharmaa, N. Singha, V. Tomara and R. Chandra, Biosens. Bioelectron., 2018, 107, 76-93. 